Sādhanā, Vol. 9, Part 3, November 1986, pp. 191-232. (C) Printed in India.

\title{
Cryogenic refrigeration methods for low and ultra-low temperatures - a review
}

\author{
$M$ THIRUMALESHWAR* and S V SUBRAMANYAM** \\ ${ }^{*}$ Cryogenics Section, Technical Physics and Prototype Engineering \\ Division, BARC, Bombay 400 085, India \\ ** Department of Physics, Indian Institute of Science, Bangalore \\ 560012 , India
}

MS received 2 September 1985; revised 4 April 1986

\begin{abstract}
In this review, various cryogenic refrigeration methods to obtain temperatures extending down to the milliKelvin/microKelvin range are described after first explaining the concepts of a "thermodynamically ideal cycle" and the "figure of merit". The various cycles are compared with each other. Data about some of the commercially available refrigerators/cryogenerators have also been included in this review.
\end{abstract}

Keywords. Cryogenics; ultra-low temperatures; refrigeration methods.

\section{Introduction}

Cryogenics literally means "icy cold". However, generally this word connotes temperatures below $120 \mathrm{~K}$ (Barron 1966). A review of the history of the development of cryogenics is given by Mendelssohn (1966). Cryogenic technology implies the science and techniques of liquefaction, transportation and usage of cryogenic fluids such as liquid nitrogen $\left(\mathrm{LN}_{2}\right)$, liquid hydrogen $\left(\mathrm{LH}_{2}\right)$, liquid helium ( $\mathrm{LHe}$ ) etc. Developments of this technology from both the commercial and laboratory points of view are described in standard references (e.g., Mendelssohn 1966; Hoare et al 1961; Scott 1959; Croft 1976; Kurti 1971). Cryogenic refrigeration methods cover a wide spectrum from large industrial plants for production of cryogenic liquids to closed cycle helium refrigerators handling only a few watts at very low temperatures. Daniels and du Pre (1971) give specifically the requirements of such small refrigerators for cooling some electronic devices. Crawford (1970) gives a compilation of specifications of some commercially available cryogenic refrigerators.

This review, first introduces the concepts of a "thermodynamically ideal refrigeration cycle" and the "figure of merit". Next, the various cryogenic 
refrigeration methods for attaining low and ultra-low temperatures are described. Details about some of the commercially available cryogenerators/refrigerators are also presented.

\section{Thermodynamically ideal refrigeration cycle}

\subsection{Isothermal load}

Cryogenic refrigeration consists in extracting a certain amount of heat from a source at a low temperature, $T_{L}$, and delivering this heat to a high temperature heat sink at temperature, $T_{0}$. Normally, the sink is the ambient so that $T_{0}$ is the ambient temperature i.e. $300 \mathrm{~K}$. It is very well-known from thermodynamics that the "reversible Carnot cycle" is the thermodynamically ideal cycle between two given temperatures. The ideal Carnot refrigeration cycle is shown on the $T-S$ diagram in figure 1 . It consists of two reversible isothermals and two reversible adiabatics; the heat extraction and rejection occur at constant temperatures of $T_{L}$ and $T_{0}$, respectively. From the $T-S$ diagram it is clear that:

a) refrigeration produced, $Q=T_{L} \cdot \Delta S$,

b) work supplied, $W=-\left(T_{0}-T_{L}\right) . \Delta S$ and,

c) specific power requirement $=$ work required per unit of refrigeration produced, i.e., $-W / Q=\left(T_{0}-T_{L}\right) / T_{L}$.

It may be noted that $(W / Q)$ for a Carnot cycle depends only on the temperature levels of operation and is independent of the working substance.

In an actual refrigeration cycle, there will be many irreversibilities as compared to the ideal cycle because of the definite temperature gradient required for heat transfer, pressure drops, frictional heating etc. So, the specific power $(W / Q)_{\text {actual }}$ will be higher. The ratio $(W / Q)_{\text {Carnot }} /(W / Q)_{\text {actual }}$ is called the "percent Carnot" or "figure of merit" (FOM) of the system.

It is clear that FOM is always less than unity and the aim of the designer is to obtain a value as near to unity as possible. Table 1 shows the ideal Carnot work required at $300 \mathrm{~K}$ to supply one unit of refrigeration at various values of low

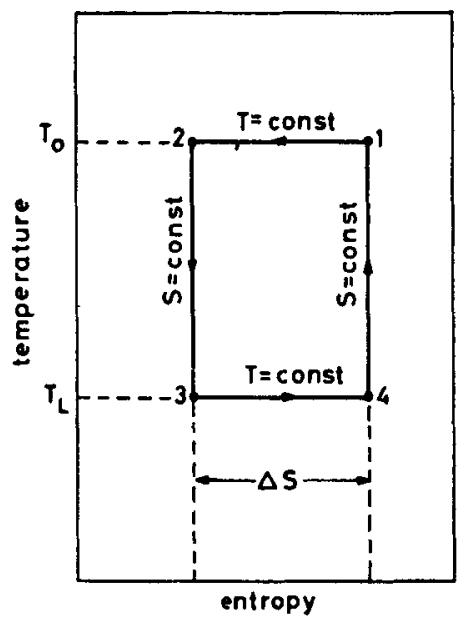

Figure 1. Carnot cycle. 
Table 1. Room temperature work requirement for cryogenic refrigeration

\begin{tabular}{ccc}
\hline $\begin{array}{c}\text { Temperature } \\
(\mathrm{K})\end{array}$ & $\begin{array}{c}\text { Ideal Carnot work } \\
(W / W)\end{array}$ & $\begin{array}{c}\text { Practical work } \\
\text { requirement }(W / W)\end{array}$ \\
\hline 80 & $2 \cdot 75$ & $10 \cdot 0$ \\
20 & $14 \cdot 00$ & $70 \cdot 0$ \\
14 & $20 \cdot 00$ & $150 \cdot 0$ \\
4 & $74 \cdot 00$ & $1500 \cdot 0$ \\
2 & $150 \cdot 00$ & $6000 \cdot 0$ \\
$10^{-3}$ & $3 \times 10^{5}$ & MegaWatts \\
\hline
\end{tabular}

Source: Bailey (1971).

temperature, $T_{L}$ (Bailey 1971). The third column in this table gives the values of approximate work required in some practical systems. It can be seen that as the temperature level is reduced, work required per unit of refrigeration increases drastically. It should be particularly noted that heat inleaks to very low temperature regions (i.e. $20 \mathrm{~K}-4 \cdot 2 \mathrm{~K}$ ) can be very 'expensive' and should be minimised by all possible means.

\subsection{Isobaric load}

It should be remembered that in the ideal Carnot cycle considered above, all the refrigeration is produced at a constant temperature $T_{L}$. However, this may not be the case always. There are practical cases where the refrigeration is produced at varying temperature levels, say increasing from $T_{L 1}$ to $T_{L 2} \mathrm{e} . \mathrm{g}$. as in the continuous cooling of a Joule-Thomson stream by an expansion engine. In such a case, if a Carnot efficiency based on the lowest temperature $T_{L 1}$ is used for comparison, it would mean that an ideal with too low a performance has been used. Such a case of an "ideal isobaric refrigerator" has been considered by Jacobs (1962) (see figure 2) and the expression derived by him for $W / Q$ for that case is as follows:

$$
(W / Q)_{\text {idcal isubaric }}=\left[T_{0} /\left(T_{L, 2}-T_{L 1}\right) / \ln \left(T_{L 2} / T_{L, 1}\right)\right]-1
$$

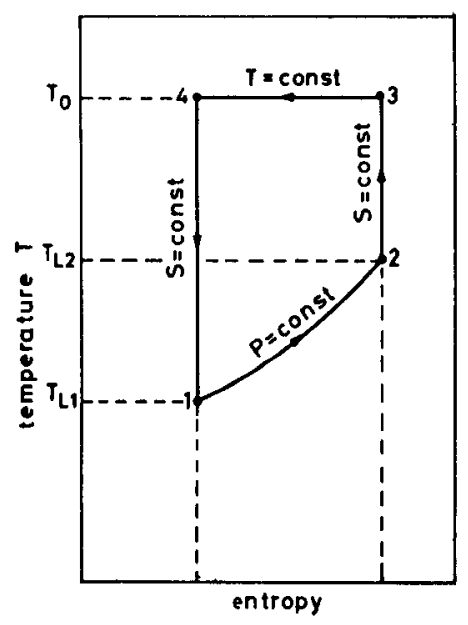

Figure 2. Isobaric source refrigerator. 
i.e., the constant temperature of the refrigeration load of the Carnot cycle is replaced by the log mean temperature of the refrigerant supplying the refrigeration.

\section{Production of low temperatures}

\subsection{Various refrigeration methods}

Gifford (1967) has given a comprehensive list of many useful refrigeration methods along with the temperature range of their applications (see table 2). It can be seen that not all of them are useful at cryogenic temperatures i.e. below $100 \mathrm{~K}$. Further, vapour compression and absorption systems belong to the category of the generally used commercial refrigeration field. Adiabatic demagnetization and $\mathrm{He}^{3} / \mathrm{He}^{4}$ dilution methods need precooling by other methods and are for operation in the milliKelvin temperature range. These are useful mainly for research. With this in mind, if we draw a list of really useful methods at cryogenic temperatures, the list reduces to that of table 3 . Also, it is worth noting that as compared to ordinary refrigeration, one has to face some special difficulties while trying to attain cryogenic temperatures (Gifford 1970):

a) no single fluid to cover the entire range of cryogenic temperatures;

b) elastic seals (like rubber) become hard and brittle;

c) freezing of lubricating oils;

d) some metals (e.g. mild steel) become brittle;

e) at temperatures below the triple point of air, air itself becomes a plugging impurity. If air is present as an impurity in the case of hydrogen, neon or helium systems, it can freeze and cause plugging of the passages of heat exchangers or J-T (Joule-Thomson) valves;

f) necessity of efficient, sealed thermal insulation. Below the liquefaction point of air, if air leaks into insulation space the same will condense and cause high heat leaks;

Table 2. Useful refrigeration methods

\begin{tabular}{lr}
\hline Method & Temperature range (K) \\
\hline Thermoelectric & $280-300$ \\
Hilsch or Ranque tube & $260-300$ \\
Vapour compression & $250-300$ \\
Vapour compression (cascade) & $80-250$ \\
Absorption & $250-300$ \\
Joule-Thomson system & $1-150$ \\
Claude cycle & $1-150$ \\
Expansion engines & $10-150$ \\
Expansion turbines & $10-150$ \\
Stirling cycle/Brayton cycle & $10-150$ \\
Gifford-McMahon cycle & $10-150$ \\
Solvay cycle & $10-150$ \\
Pulse tube refrigeration & $50-150$ \\
Adiabatic demagnetization & $\mathrm{mK}-1 \mathrm{~K}$ \\
He ${ }^{3}$ dilution & $\mathrm{mK}-1 \mathrm{~K}$ \\
\end{tabular}

Source: Gifford (1967) 
Table 3. Useful methods at cryogenic temperatures

\begin{tabular}{|c|c|c|c|}
\hline Methods & $\begin{array}{l}\text { Temperature range } \\
(\mathrm{K})\end{array}$ & $\begin{array}{c}\text { Best size } \\
\text { application }\end{array}$ & $\begin{array}{c}\text { Heat exchange } \\
\text { means }\end{array}$ \\
\hline Joule-Thomson & $1-150$ & Large and very small & Heat exchanger \\
\hline Claude cycle & $10-150$ & Large and very small & Heat exchanger \\
\hline $\begin{array}{l}\text { Claude cycle with } \\
\text { expansion engine }\end{array}$ & $10-150$ & Large & Heat exchanger \\
\hline $\begin{array}{l}\text { Claude cycle with } \\
\text { expansion turbine }\end{array}$ & $10-150$ & Very large & Heat exchanger \\
\hline $\begin{array}{l}\text { Stirling/Brayton } \\
\text { cycle }\end{array}$ & $10-150$ & Small/large & $\begin{array}{l}\text { Regenerator/heat } \\
\text { exchanger }\end{array}$ \\
\hline Gifford-McMahon cycle & $10-150$ & Small/moderate & Regenerator \\
\hline Solvay cycle & $10-150$ & Small/moderate & Regenerator \\
\hline Pulse tube & $50-150$ & Small/spotcooling & Regenerator \\
\hline \multicolumn{4}{|l|}{ Adiabatic } \\
\hline demagnetization & $\mathrm{mK}-1 \mathrm{~K}$ & & \\
\hline $\mathrm{He}^{3}$ dilution & $\mathrm{mK}-1 \mathbf{K}$ & & \\
\hline
\end{tabular}

Source: Gifford (1967)

g) heat capacities of normal solids become very small - this means that even a small heat leak can cause considerable temperature rise. Drop in values of heat capacity as temperature falls makes it difficult to fabricate good thermal regenerators;

h) thermal conductivity of pure and impure metals/alloys is generally low at low temperatures.

\subsection{Cryogenic refrigeration methods}

In this section, we will consider the following cryogenic refrigeration methods: (i) use of a liquid cryogen; (ii) Joule-Thomson system; (iii) Claude cycle, with (a) an expansion engine, or (b) an expansion turbine; (iv) modified Brayton cycle; (v) Stirling cycle; (vi) Gifford-McMahon cycle (single volume and double volume); (vii) Solvay cycle; (viii) free displacer cycle; (ix) Vuilleumier cycle; (x) Pulse tube refrigeration; (xi) adiabatic demagnetization; (xii) $\mathrm{He}^{3} / \mathrm{He}^{4}$ dilution; and (xiii) Pomeranchuk cooling.

As already mentioned, adiabatic demagnetization, $\mathrm{He}^{3} / \mathrm{He}^{4}$ dilution and Pomeranchuk cooling methods are for operation in the milliKelvin temperature ranges and are used mainly for research applications.

3.2a Use of a liquid cryogen: The simplest method to obtain low temperatures is to use a liquid cryogen. Liquid nitrogen $\left(\mathrm{LN}_{2}\right)(\mathrm{B} . \mathrm{P} . \approx 77 \mathrm{~K}$ at one atm pressure) and liquid helium $(\mathrm{LHe})$ (B.P. $=4.2 \mathrm{~K}$ at one atm pressure) are the most commonly used cryogens. Liquid hydrogen has a normal boiling point of $20 \mathrm{~K}$. Generally, its use in the laboratory is restricted because of safety hazards. Some salient properties of these three fluids are given in table 4 (Cryogenic data chart 1969). If $\mathrm{LN}_{2}$ is to be used in small quantities and for short durations, then the same can be stored in Thermocole dewars; but, if the experiments are to be conducted for longer durations, then a suitable cryostat with vacuum insulation should be used. If LHe is being used, it is important to design the cryostat carefully for minimum heat leak since L.He has very low heat of evaporation $\left(\approx 21 \mathrm{~J} / \mathrm{g}\right.$ or $\left.2.6 \mathrm{~J} / \mathrm{cm}^{3}\right)$ i.e. 1 Watt of heat leak would evaporate about 1.4 litres of liquid per hour. Further, helium is 
Table 4. Properties of $\mathrm{LHe}, \mathrm{LH}_{2}$ and $\mathrm{LN}_{2}$

\begin{tabular}{|c|c|c|c|}
\hline Property & $\mathrm{He}^{4}$ & $\overline{\mathrm{H}_{2}}$ & $\mathbf{N}_{2}$ \\
\hline $\begin{array}{l}\text { Molecular weight } \\
\text { Boiling point (K) } \\
\text { Melting point (K) }\end{array}$ & $\begin{array}{c}4 \cdot 003 \\
4 \cdot 2 \\
4 \cdot 2 \\
(140 \mathrm{~atm})\end{array}$ & $\begin{array}{l}2.016 \\
20 \cdot 39 \\
13.98\end{array}$ & $\begin{array}{l}28 \cdot 016 \\
77 \cdot 35 \\
63 \cdot 14\end{array}$ \\
\hline $\begin{array}{l}\text { Liquid density } \\
\text { at B.P. }\left(\mathrm{g} / \mathrm{cm}^{3}\right)\end{array}$ & 0.125 & 0.071 & 0.808 \\
\hline $\begin{array}{l}\text { Gas density } \\
\text { at } 0^{\circ} \mathrm{C}, 1 \text { atom }(\mathrm{g} / \mathrm{l})\end{array}$ & 0.1785 & 0.0899 & 1.250 \\
\hline $\begin{array}{l}\text { Vapour density at } \\
\text { B.P. }(\mathrm{g} / \mathrm{l})\end{array}$ & 17.0 & 1.286 & $4 \cdot 415$ \\
\hline $\begin{array}{l}\text { Latent heat of } \\
\text { vapourisation }(\mathrm{J} / \mathrm{g})\end{array}$ & 20.9 & 443.0 & $198 \cdot 0$ \\
\hline $\begin{array}{l}\text { Latent heat of fusion } \\
(\mathrm{J} / \mathrm{g}) \\
\text { Critical temperature (K) }\end{array}$ & $\begin{array}{r}30 \cdot 5 \\
5 \cdot 2\end{array}$ & $\begin{array}{l}58 \cdot 2 \\
33 \cdot 19\end{array}$ & $\begin{array}{r}25 \cdot 5 \\
126 \cdot 1\end{array}$ \\
\hline $\begin{array}{l}\text { Critical pressure (atm) } \\
\text { Vapour pressure of solid } \\
\text { at melting point (mm of } \mathrm{Hg})\end{array}$ & $\begin{array}{c}2 \cdot 26 \\
-\end{array}$ & $\begin{array}{l}12.98 \\
54.0\end{array}$ & $\begin{array}{l}33.5 \\
96.5\end{array}$ \\
\hline
\end{tabular}

Source: Cryogenic Data Chart (1969).

rather costly and should be conserved by collecting the evaporated gas in gas bags. In general, before we proceed to design a cryostat, the following questions should be answered (White 1968):

a) The temperature of operation - Is temperature to be varied over a given range or are the operations at $90 \mathrm{~K}, 77 \mathrm{~K}$ and $4.2 \mathrm{~K}$ sufficient?

b) Is it permissible for the object to be cooled to come in contact with the cryogenic liquid/gas?

c) The nature of the specific experiment being conducted - for example, measurement of specific heat, thermal conductivity or X-ray diffraction etc.

d) Are any windows to be provided in the cryostat for passage of $X$-rays, neutrons etc.?

Several commercial models of cryostats are available and these have detachable "tails" which can be fixed to the LHe bath of the cryostat, depending upon the experiment (Product Bulletins 1977, 1981, 1982, 1983a).

The following points in connection with the design of an LHe cryostat are worth noting:

(a) Use thin-walled (typically $0.5 \mathrm{~mm}$ thick) and long stainless steel tubes for the neck to reduce the heat conduction through it $(Q=-k \cdot A \cdot \Delta T / \Delta x)$

b) Have an $\mathrm{LN}_{2}$ shield around the $\mathrm{LHe}$ container so that radiation to the $\mathrm{LHe}$ container is from $77 \mathrm{~K}$ rather than from $300 \mathrm{~K}$. This reduces the radiation heat load about 200 times since the same is proportional to the 4th power of absolute temperature.

c) Surfaces opposite each other should be well-polished and silver or gold plated to reduce the emissivity.

d) Make effective use of refrigeration available in helium gas between $4.2 \mathrm{~K}$ and $300 \mathrm{~K}$ (about $1400 \mathrm{~J} / \mathrm{g}$ i.e. about 70 times its latent heat of evaporation) in cooling the neck, electrical leads etc. Put baffles in the neck to impede the outflow of 
Table 5. Enthalpy of materials $(\mathrm{J} / \mathrm{g})$

\begin{tabular}{|c|c|c|c|c|}
\hline \multirow[b]{2}{*}{ Element } & \multicolumn{4}{|c|}{ Temperature (K) } \\
\hline & 4 & 20 & 77 & 300 \\
\hline Aluminium & $0 \cdot 000463$ & $0 \cdot 048$ & $8 \cdot 40$ & $170 \cdot 4$ \\
\hline Copper & 0.00013 & 0.034 & 5.45 & $79 \cdot 2$ \\
\hline Iron & 0.00742 & 0.0316 & $3-43$ & $81 \cdot 1$ \\
\hline Titanium & $0 \cdot 000559$ & $0 \cdot 040$ & $5 \cdot 69$ & $101 \cdot 4$ \\
\hline
\end{tabular}

evaporated gas so that it comes in contact with the neck and the leads for a longer time; it also reduces the direct radiation funneling into the liquid.

Amount of cryogen evaporated depends upon the heat load and the latent heat of the liquid (and the effective utilisation of the refrigeration available in the evaporated gas, in the case of helium) Heat load depends on the mass, specific heat and the temperature range over which cooling is done. Table 5 gives the enthalpy data of some commonly used materials at $4 \mathrm{~K}, 20 \mathrm{~K}, 77 \mathrm{~K}$ and $300 \mathrm{~K}$, and table 6 gives the values of $(k . \Delta T)$ of some commonly used materials over the normally required temperature ranges (Product Bulletin 1978a). These data are useful for calculating the conduction losses through the neck, supports etc.

In the case of a LHe bath, if the mass of the evaporated gas $m_{e}$ is known, then the value of heat load $Q_{L}$ can be calculated from the following formula assuming that only the latent heat is utilised:

$$
Q_{L}=m_{e} \cdot h_{f g} /\left(1-v_{1} / v_{v}\right) .
$$

This formula takes into account the amount of vapour that remains inside the container over the liquid; this amount is significant since the density of saturated helium vapour is only one-eighth that of the saturated liquid.

Temperatures lower than $4.2 \mathrm{~K}$ (B.P. of LHe) can be obtained by pumping over a liquid bath. Temperatures of the order of $1 \mathrm{~K}$ are obtained by pumping over a $\mathrm{He}^{4}$ bath and $0.3 \mathrm{~K}$, by pumping over a $\mathrm{He}^{3}$ bath. To go to still lower temperatures by this method becomes impracticable due to the difficulty in pumping out the large amount of vapours generated. Rose-Innes (1973) has explained the design aspects of these cryostats in detail, as also the use of $\mathrm{He}^{3}$ and $\mathrm{He}^{4}$.

Table 6. Values of thermal conductivity $\times$ temperature difference $(k . \Delta T)(\mathrm{W} / \mathrm{cm})$

\begin{tabular}{lccc}
\hline & \multicolumn{3}{c}{ Temperature range (K) } \\
\cline { 2 - 4 } Material & $300-4$ & $300-20$ & $300-77$ \\
\hline Aluminium & 728 & 700 & 505 \\
$\quad(99 \%$ pure) & & & \\
Copper (ETP) & 1,614 & 1,480 & 929 \\
Stainless steel & $30 \cdot 6$ & 30.4 & $27 \cdot 3$ \\
Titanium alloy & 16.5 & 16.4 & 14.5 \\
(Ti-5, Al-2.5, Sn) & & & 0.570 \\
Teflon & 0.702 & 0.686 & 0.570 \\
\hline
\end{tabular}

Source: Product Bulletin (1978a). 
3.2b Joule-Thomson (J.T) liquefier/refrigerator: A schematic diagram of a J-T system along with the $T-S$ diagram is shown in figure 3 (Barron 1966). Here, the gas is compressed isothermally ( 1 to 2 ), cooled in a heat exchanger ( 2 to 3 ) by the returning cold stream and expanded into an evaporator isenthalpically ( 3 to 4$)$ in a Joule-Thomson valve. During expansion, a part of the gas-stream liquefies. This liquid supplies the isothermal refrigeration when it boils.

Isothermal compressor work,

$$
W_{c}=-m \cdot R \cdot T_{0} \cdot \ln \left(P_{2} / P_{1}\right) .
$$

To find the refrigeration produced, $Q_{l}$, the I law is applied to the system consisting of the heat exchanger, the J-T valve, and the evaporator; we get

$$
Q_{L}=m .\left(h_{1}-h_{2}\right) \text {, }
$$

where, $h_{1}, h_{2}$, are enthalpies at inlet and discharge of compressor, respectively.

Work per unit of refrigeration is given by

$$
W_{c} / Q_{L}=-R \cdot T_{0} \cdot \ln \left(P_{2} / P_{1}\right) /\left(h_{1}-h_{2}\right) .
$$

Temperature drop upon expansion through the J-T valve depends upon the properties of the fluid, inlet pressure, final pressure and the temperature before the expansion. J-T expansion is characterised by the Joule-Thomson coefficient defined as follows:

$$
\mu_{\mathrm{JT}}=(\partial T / \partial P)_{h} .
$$

This coefficient may be positive, negative or zero; and it is clear that for cooling to be produced upon expansion through a J-T valve, $\mu_{\mathrm{JT}}$ should be positive. The locus of the points where $\mu_{\mathrm{JT}}$ is equal to zero is called the "inversion curve". Expansion from a temperature above the maximum inversion temperature will always 'result in heating instead of cooling. However, at ambient temperature $(300 \mathrm{~K})$, most of the gases are below their maximum inversion temperature, except the following: (i) helium $\left(T_{i}=40 \mathrm{~K}\right)$, (ii) hydrogen $\left(T_{i}=202 \mathrm{~K}\right)$, and (iii) neon $\left(T_{i}=250 \mathrm{~K}\right)$. Therefore, it is necessary that these three gases are precooled below their maximum inversion temperatures before being expanded in a $\mathrm{J}$-T valve.

Some of the salient features of the J-T system may be summarised as follows (Strobridge 1968; Zemansky 1968):

i) A simple system with no low temperature moving parts to lubricate.
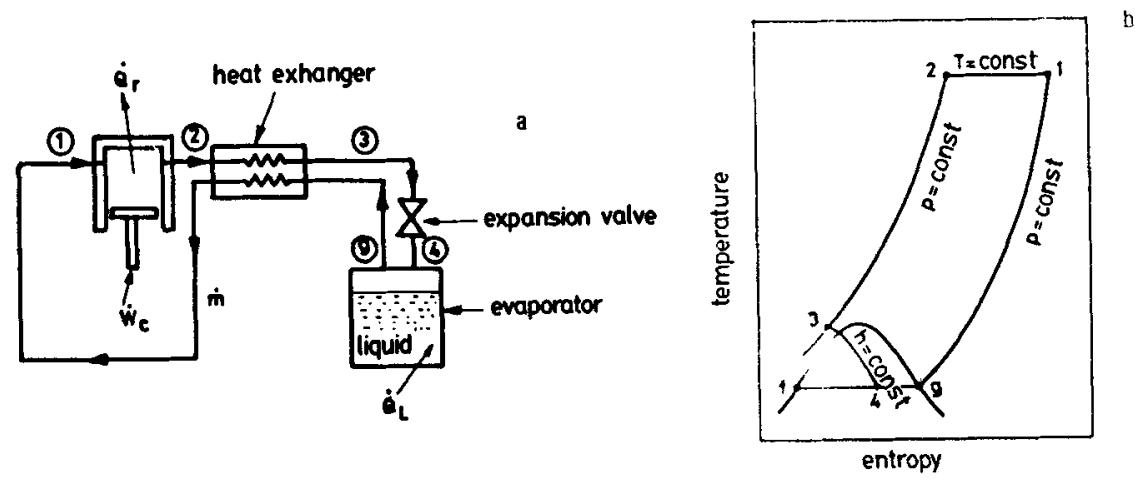

Figure 3a. Joule-Thomson refri ator. b. T-S diagram for J-T cycle. 
ii) It is more advantageous at lower temperatures since from the $T-S$ diagram it can be seen that lower the temperature, the larger is the temperature drop for a given pressure drop.

iii) The J-T valve is an essential component of the liquefaction stage of a helium liquefier. It is impractical to use other methods of expansion such as an expansion engine or turbine when the liquid is formed.

iv) Generally, high operating pressures (for example, of the order of $200 \mathrm{~atm}$ with air).

v) Low liquefaction fraction, if used as liquefier (about $7 \%$ of total flow for air liquefaction).

vi) Expansion through a J-T value is highly irreversible and is thermodynamically less efficient as compared to expansion in a work producing device such as an expansion engine or a turbine. This reflects itself in a low figure of merit (of the order of $6 \%$ to $10 \%$ ).

vii) Sensitive to impurities - J-T valves get plugged by frozen impurities

Dean \& Mann (1965) have made extensive calculations regarding the characteristics of the J-T system. They considered a wide range of parameters such as operating pressure, precooling temperature and temperature difference at the warm end of the heat exchanger. Refrigeration was assumed to be produced isothermally at the normal boiling point temperature. Values of $\left(W_{c} / Q_{L}\right)$ and flow rate required in gram moles per second to produce $1 \mathrm{~W}$ of useful refrigeration were calculated for each set of parameters.

Using the principle of J-T expansion, novel cryotips or "minicoolers" have been manufactured by several companies. For example, Donabedian (1972) has compared the performance of such J-T refrigerators, used primarily for aerospace applications, manufactured by Air Products and Chemicals Inc., Hymatic Eng. Co. and Hughes Aircraft Company. These are typically small capacity cryocoolers operating down to $4.2 \mathrm{~K}$, used for spot cooling detectors etc. They use commercially available high purity gases from standard bottles (nitrogen, hydrogen or helium). While using hydrogen or helium, refrigeration required for precooling is provided by a separate $\mathrm{J}-\mathrm{T}$ circuit using nitrogen. As an example, some particulars of the minicoolers produced by Air Products and Chemicals Inc. (Product Bulletin 1978a), are given in table 7.

Table 7. Minicoolers produced by Air Products \& Chemicals Inc., USA

\begin{tabular}{|c|c|c|c|c|c|c|c|}
\hline Model & $\begin{array}{l}\text { Capacity } \\
\text { (W) }\end{array}$ & $\begin{array}{c}\text { Temperature } \\
\text { (K) }\end{array}$ & $\begin{array}{c}\text { Gas } \\
\text { consumption } \\
(\mathrm{SCFM})^{\bullet}\end{array}$ & $\begin{array}{c}\mathbf{L N}_{2} \\
(1 / \mathrm{hr})\end{array}$ & $\begin{array}{c}\text { Heat } \\
\text { exchanger }\end{array}$ & $\begin{array}{l}\text { Time per } \\
\text { standard } \\
\text { cycle } \\
\text { (hr) }\end{array}$ & $\begin{array}{c}\text { Empty weight } \\
(\mathrm{kg})\end{array}$ \\
\hline AC-1 & 7 & $68-300$ & $\mathrm{GN}_{2}: 0.8$ & - & \multirow{3}{*}{$\begin{array}{l}\text { Coiled } \\
\text { finned } \\
\text { tubing }\end{array}$} & 3 to 6 & 0.5 \\
\hline AC-2 & 6 & $16-300$ & $\begin{array}{l}\mathrm{GH}_{2}: 0.8 \\
\mathrm{GN}_{2}: 0.9\end{array}$ & - & & \multirow{2}{*}{$\begin{array}{l}\mathrm{H}_{2}: 6 \\
\mathrm{~N}_{2}: 8 \\
\mathrm{H}_{2}: 6 \\
\mathrm{H}_{2}: 4 \\
\mathrm{He}: 4\end{array}$} & 0.7 \\
\hline $\begin{array}{l}\text { AC-2L } \\
\text { AC-3L }\end{array}$ & $\begin{array}{c}6 \\
500 \mathrm{~mW} \\
\text { at } 4.4 \mathrm{~K} \text {; } \\
4 \mathrm{~W} \text { at } \\
22 \mathrm{~K}\end{array}$ & $\begin{array}{r}16-300 \\
3 \cdot 6-300\end{array}$ & $\begin{array}{l}\mathrm{GH}_{2}: 1 \cdot 0 \\
\mathrm{GHe}: 1 \cdot 3 \\
\mathrm{GH}_{2}: 0.9\end{array}$ & $\begin{array}{l}0.5 \\
0.5\end{array}$ & & & $\begin{array}{l}10 \\
10\end{array}$ \\
\hline
\end{tabular}

Source: Product Bulletin (1978a). "Standard cubic foot per minute 
3.2c Claude cycle liquefier/refrigerators: A schematic diagram of the system and the cycle on the $T-S$ diagram are shown in figure 4 (Barron 1966). Here, the gas is compressed isothermally in a compressor (1-2) and cooled in a series of three heat exchangers (2-5). After the first heat exchanger, a part of the high pressure stream (about $70 \%$ ) is expanded through an expander and the resulting cold gas joins the return gas-stream as shown. The remainder of the high pressure stream, after getting precooled in the other two heat exchangers, is expanded through the $\mathrm{J}-\mathrm{T}$ valve (5-6) and a fraction of the gas liquefies. This liquid provides the isothermal refrigeration at its boiling point and the return gas is passed through the heat exchangers as shown.

Applying the I law to the system consisting of the heat exchangers, expander, expansion valve and evaporator,

$$
Q_{L}-W_{e}=\dot{m} \cdot\left(h_{1}-h_{2}\right),
$$

where $W_{e}$ is the work output from the expander.

Applying the I law to the expander,

$$
-W_{e}=\dot{m}_{e} \cdot\left(h_{e}-h_{3}\right)
$$

where, $\dot{m}_{e}=$ mass flow rate through the expander, $h_{3}, h_{e}=$ enthalpies before and after expansion through the expander,

or

$$
Q_{L} / \dot{m}=\left(h_{1}-h_{2}\right)+\dot{m}_{e} \cdot\left(h_{3}-h_{e}\right) / \dot{m} .
$$

For isothermal compression in the compressor, we have

$$
W_{c} / \dot{m}=-R . T_{0} \cdot \ln \left(P_{2} / P_{1}\right),
$$

and specific power requirement is given by

$$
W / Q_{L}=-R \cdot T_{0} \cdot \ln \left(P_{2} / P_{1}\right) /\left[\left(h_{1}-h_{2}\right)+\dot{m}_{e} \cdot\left(h_{3}-h_{e}\right) / \dot{m}\right] .
$$

Sometimes, 2 or 3 expanders are used instead of one expander. Also, the work produced in the expander can be utilised to compress the gas; however, this is not generally done and the work produced is absorbed in a brake. In the case of the
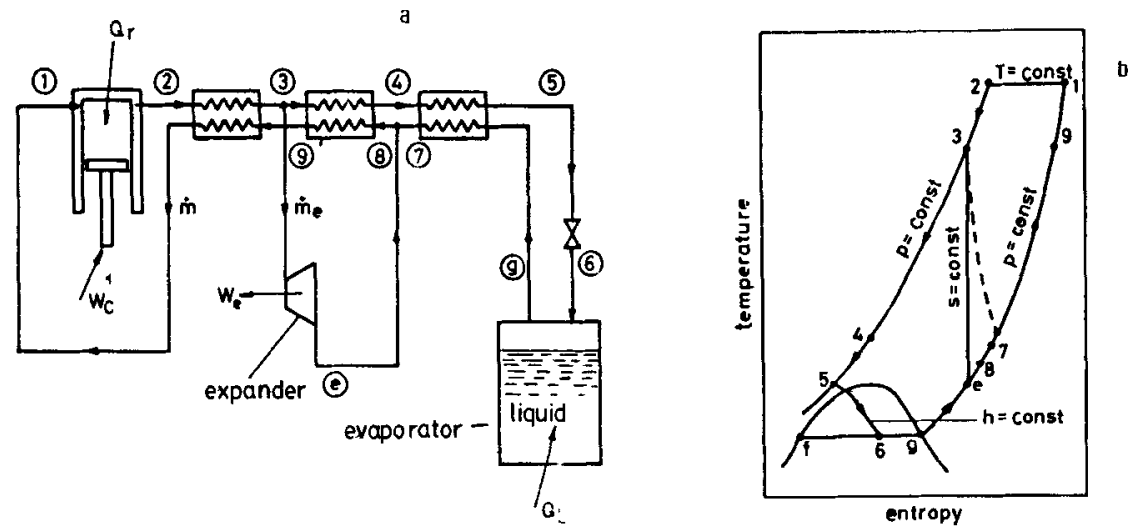

Figure 4a. Claude cycle refrigerator. b. $T-S$ diagram for Claude cycle. 
Claude cycle, the major portion of the refrigeration is produced by the expander and not by the J-T valve. Some of the advantages of the Claude cycle are:

(i) Moderate pressure (30 to $40 \mathrm{~atm}$ for air and 15 to $20 \mathrm{~atm}$ for $\mathrm{He}$ );

(ii) Gas is expanded isentropically in the expander. Therefore, thermodynamically it is less "lossy". This is reflected in a higher value of figure of merit (about $25 \%$ for air liquefaction systems);

(iii) Since cooling is produced by extracting external work, it is certain that gas will always cool upon expansion through an expander. This is not so in the case of J-T expansion because of the constraint of inversion temperature as already explained. The expander used in the Claude system may be either a reciprocating type expansion engine or a turbine.

(i) Claude cycle with reciprocating type expansion engine: Claude, after whom the cycle is named, used an expansion engine with leather seals in an air liquefaction system built by him in 1902. In 1946, the first commercially produced laboratory package helium liquefiers appeared on the market. These were produced by Arthur D Little Inc. USA (ADL) and were based on the design of Sam Collins of MIT (Collins \& Cannaday 1958). Collins helium liquefier has two expanders of the piston and cylinder type. About $30 \%$ of total flow is expanded in the first engine from about $60 \mathrm{~K}$ to $30 \mathrm{~K}$ and about $55 \%$ of total flow is expanded in the 2 nd engine from about $15 \mathrm{~K}$ to $9 \mathrm{~K}$ and the remaining $15 \%$ of the flow passes through the $\mathrm{J}-\mathrm{T}$ stage. The engines are of an ingenious design with the piston rod always in tension, making it light and flexible, thus reducing the heat inleak by conduction. Piston (with peripheral grooves) and cylinder are made of nitrided nitralloy steel and the clearance is about $0.05 \mathrm{~mm}$ on a bore of $25 \mathrm{~mm}$. Valves have leather seats and their operating rods are also in tension. The heat exchanger consists of a helix of finned tube enclosed between two near-cylindrical thin stainless steel sheets.

The ADL-Collins helium liqueficr operated at $15 \mathrm{~atm}$ pressure and there was provision to enhance the liquefaction rate by using $\mathrm{LN}_{2}$ for precooling. There were basically two versions: One version produced about $2 \mathrm{l} / \mathrm{hr}$ of $\mathrm{LHe}$ without $\mathrm{LN}_{2}$ precooling and about $5 \mathrm{l} / \mathrm{hr}$ with $\mathrm{LN}_{2}$ precooling, and consumed about $13 \mathrm{~kW}$ of power. The other version produced about $3 \mathrm{l} / \mathrm{hr}$ of $\mathrm{LHe}$ without $\mathrm{LN}_{2}$ precooling and about $9 \mathrm{l} / \mathrm{hr}$ of $\mathrm{LHe}$ with $\mathrm{LN}_{2}$ precooling, consuming about $26 \mathrm{~kW}$ of power. In both cases, when used, the $\mathrm{LN}_{2}$ requirement was $10-12 \mathrm{l} / \mathrm{hr}$.

Cryogenic Technology Inc. (formerly Arthur D Little Inc.) have introduced Model $1400 \mathrm{Helium} \mathrm{liquefier/refrigerator} \mathrm{(Product} \mathrm{Bulletin} \mathrm{1970).} \mathrm{It} \mathrm{has} \mathrm{two}$ expansion engines and the output is $5-20 \mathrm{l} / \mathrm{hr}$ of LHe or $20-50 \mathrm{~W}$ of refrigeration at $4.2 \mathrm{~K}$ depending on whether one or two compressors are used and whether $\mathrm{LN}_{2}$ is used. Operation is automatic and the built-in purification system allows upto $20 \%$ of air as impurity in the incoming helium gas.

Doll \& Eder (1964), developed another novel piston and cylinder type of expansion engine, used in the helium liquefiers manufactured by the Linde Co. of West Germany. In this expansion engine, inlet and exhaust valves are formed by providing suitable ports in the cylinder walls. Movement of the piston itself either covers or uncovers these ports. One of the disadvantages is that the clearance required between the piston and the cylinder is very small (of the order of 1-3 microns as compared to 50 microns in Collins engines) to avoid shortcircuiting of gas from 
the high pressure to the low pressure port. Standard models of helium liquefiers/refrigerators manufactured by $\mathrm{M} / \mathrm{s}$. Linde produce $\mathrm{LHe}$ in the range $4 \mathrm{l} / \mathrm{hr}$ to $160 \mathrm{l} / \mathrm{hr}$ or refrigeration (at $4.2 \mathrm{~K}$ ) in the range $15 \mathrm{~W}$ to $550 \mathrm{~W}$. Power consumption varies from $18 \mathrm{~kW}$ to $400 \mathrm{~kW}$ (Patzelt et al 1973; Product Bulletin 1983c).

(ii) Claude cycle with expansion turbine: Instead of reciprocating expansion engines, turbo-expanders have been used to produce cooling. Generally, these are for medium pressures and large through-puts. Because of the low density of helium gas, the turbine has to operate at very high speeds $(300,000$ to 600,000 r.p.m.); so, wear of bearings is a major factor to be considered during the design. Both oil lubricated and pressurised gas lubricated bearings have been used (Patzelt et al 1973). A turbine developed by National Bureau of Standards, Boulder, Colarado, USA, has a shaft diameter of $8 \mathrm{~mm}$ and a design speed of 600,000 r.p.m. at $30 \mathrm{~K}$ inlet temperature (Mann et al 1963). Sixsmith \& Wilson (1964) describe the turboexpander suitable for helium which operates at 500,000 r.p.m. using externally pressurised gas lubricated bearings. Sixsmith (1984) has also given a comprehensive review about the development of miniature cryogenic expansion turbines by Linde A G of Germany, University of Reading, NBS Washington, Sulzer Bros., L'Air Liquide, British Oxygen Co., and Crear R \& D. Clarke \& Gardner (1967) have explained the turboexpander developed at the British Oxygen Co. (BOC), UK. BOC have built commercial helium liquefiers (range: $15 \mathrm{l} / \mathrm{hr}$ to $40 \mathrm{l} / \mathrm{hr}$ ) using these turboexpanders (Product Bulletin 1978b). Helium liquefiers/ refrigerators built by Sulzer Bros. (Switzerland), known as "Turbocryofridges", are described by Eber (1980). Sulzer "Turbocryofridges" (TCF-100 and TCF-200) are available as liquefiers $(10 \mathrm{l} / \mathrm{hr}-300 \mathrm{l} / \mathrm{hr})$ or refrigerators $(40 \mathrm{~W}$ to $1000 \mathrm{~W}$ at $4.2 \mathrm{~K}$ ) (Product Bulletin 1979b). The largest LHe plant to date $(4700 \mathrm{l} / \mathrm{hr}$ ) is supplied by them to Fermilab, USA. Details about some standard Claude cycle helium liquefiers/refrigerators produced commercially are given in table 8 .

Donabedian (1972) has compiled data on the turbomachinery refrigeration systems developed by General Electric, Garrett AiResearch, A D Little, Hymatic Eng. and Air products, mainly for space borne and military applications. He has also given the power and weight estimates for $4.4 \mathrm{~K}$ and $20 \mathrm{~K}$ turbomachinery refrigerators based on the studies conducted by the General Electric Co. Further, he states that "performance of miniature turbomachinery refrigerators is a strong function of their capacity since the working fluid flow rates in small refrigerators are substantially lower than the normal range appropriate to turbomachinery".

As is well-known, turbine plants are normally used for large throughputs. Table 8 shows only the standard models commercially available. However, several larger plants based on the Claude cycle using one or two turbines have been built to meet specific requirements. Patzelt et al (1973) describe a Linde plant supplied to the Society for Nuclear Research, Karlsruhe, Germany, which supplies a refrigeration load of $380 \mathrm{~W}$ at $1.8 \mathrm{~K}$ with a power consumption of $700 \mathrm{~kW}$.

Major applications of such specially built plants are in the fields of high energy physics, particle accelerators and fusion research (Giger 1968; Damiani et al 1972; Giger et al 1975; Quack 1978). Giger et al (1974) describe a large helium refrigeration system for the Big European Bubble Chamber (BEBC) at CERN, Geneva. This chamber, used to track the paths of particle beams, is $3.7 \mathrm{~m}$ in 
diameter and holds 37,000 litres of liquid hydrogen; the two superconducting coils, when energized with 5700 A current, give a magnetic field of 3.5 Tesla in the usable chamber volume. The refrigeration duty is $25 \mathrm{~kW}$ at $22 \mathrm{~K}$ and $1.5 \mathrm{~kW}$ at $4.4 \mathrm{~K}$. Other applications in high energy physics are for cooling superconducting magnets for beam transport, accelerator magnets, and for cooling superconducting r.f. cavities (Pewitt 1971). Perhaps, the largest refrigeration system is that of the Fermilab Energy Doubler, described by Fowler (1982). This system consists of a large central helium liquefier $(>4000 \mathrm{l} / \mathrm{hr}$ ) and 24 satellite refrigerators $(1000 \mathrm{~W}$ each) located around a ring of $6 \mathrm{~km}$ circumference. There are nearly 1000 magnets to be cooled. Total power requirement for this system is about $11.4 \mathrm{MW}$. Tada et al (1982) describe a $350 \mathrm{l} / \mathrm{hr}, 1200 \mathrm{~W}$ helium cryogenic system for the development of Fusion technology at the Japan Atomic Energy Research Institute. The system uses two turbines and double J-T expansion and has a Carnot efficiency of $33 \%$. A helium cryogenic plant with two gas-bearing turboexpanders, used to cool the superconducting magnets of a "Piotron" for biomedical applications in the Swiss Institute for Nuclear Research, is described by Blaser \& Kurtcuoglu (1981). This system supplies $20 \mathrm{l} / \mathrm{hr}$ of LHe and $370 \mathrm{~W}$ at $4.4 \mathrm{~K}$.

3.2d Modified Brayton cycle refrigerator: The original ideal heat engine cycle conceived by George Brayton in 1873 consists of two isobaric and two isentropic processes. This cycle has been extensively used in aircraft cooling. In the modified Brayton cycle, the compression is assumed to be isothermal as compared to the isentropic compression in the original Brayton cycle. A schematic diagram of the modified Brayton cycle and the same on a $T-S$ diagram are shown in figure 5 (Strobridge 1968). Ideally, (5'-1) is isothermal compression, (1-2) is cooling in the

Table 8. Standard Claude cycle helium liquefiers/refrigerators available commercially

\begin{tabular}{|c|c|c|c|c|c|c|c|}
\hline \multirow[b]{2}{*}{ Company } & \multirow[b]{2}{*}{$\begin{array}{l}\text { Liquefaction } \\
\text { rate }(\mathrm{l} / \mathrm{hr})\end{array}$} & \multicolumn{2}{|c|}{ Refrigeration } & \multirow[b]{2}{*}{$\begin{array}{c}\mathrm{LN}_{2} \\
\text { precool }\end{array}$} & \multirow[b]{2}{*}{$\begin{array}{c}\text { Power } \\
(k W)\end{array}$} & \multirow[b]{2}{*}{$\begin{array}{l}\text { Expander/ } \\
\text { turbine }\end{array}$} & \multirow[b]{2}{*}{$\begin{array}{c}\text { Heat } \\
\text { exchanger }\end{array}$} \\
\hline & & $\begin{array}{l}\text { Capacity } \\
\text { (W) }\end{array}$ & $\begin{array}{c}\text { Temperature } \\
\text { (K) }\end{array}$ & & & & \\
\hline BOC, UK & $\begin{array}{c}17-40 \\
-\end{array}$ & $40-110$ & $\overline{4 \cdot 4}$ & $\begin{array}{l}\text { Yes/no } \\
\text { yes/no }\end{array}$ & $45-100$ & Turbine & $\begin{array}{l}\text { Brazed } \\
\text { Al plate } \\
\text { fin }\end{array}$ \\
\hline $\begin{array}{l}\text { CTI, USA } \\
\text { (Model 2000) }\end{array}$ & $30-100$ & $\begin{array}{c}140-400 \\
1000-2000\end{array}$ & $\begin{array}{c}4 \cdot 5 \\
20\end{array}$ & yes/no & $50-200$ & Expander & $\begin{array}{l}\text { Counter } \\
\text { flow, } \\
\text { finned } \\
\text { tube }\end{array}$ \\
\hline $\begin{array}{l}\text { Sulzer Bros. } \\
\text { (Model TCF-100) }\end{array}$ & $10-40$ & $40-180$ & $\overline{4 \cdot 5}$ & $\begin{array}{l}\text { yes/no } \\
\text { yes/no }\end{array}$ & $55-100$ & Turbine & $\begin{array}{l}\text { Brazed } \\
\text { Al plate } \\
\text { fin }\end{array}$ \\
\hline Linde, Germany & $4-160$ & $\begin{array}{c}- \\
15-550\end{array}$ & - & $\begin{array}{l}\text { yes/no } \\
\text { yes/no }\end{array}$ & $18-400$ & Expander & $\begin{array}{l}\text { Copper } \\
\text { pipe, } \\
\text { cross } \\
\text { fow }\end{array}$ \\
\hline Air Products, USA & $5-18$ & $\frac{-}{15-70}$ & - & $\begin{array}{l}\text { yes/no } \\
\text { yes/no }\end{array}$ & $20-40$ & Expander & \\
\hline $\begin{array}{l}\text { L'Air Liquide, } \\
\text { France }\end{array}$ & $40-80$ & $140-220$ & $\overline{4 \cdot 4}$ & $\begin{array}{l}\text { yes/no } \\
\text { yes/no }\end{array}$ & & Turbine & $\begin{array}{l}\text { Brazed, } \\
\text { Al plate } \\
\text { fin }\end{array}$ \\
\hline
\end{tabular}

Source: Product Bulletins of the Companies concerned. 

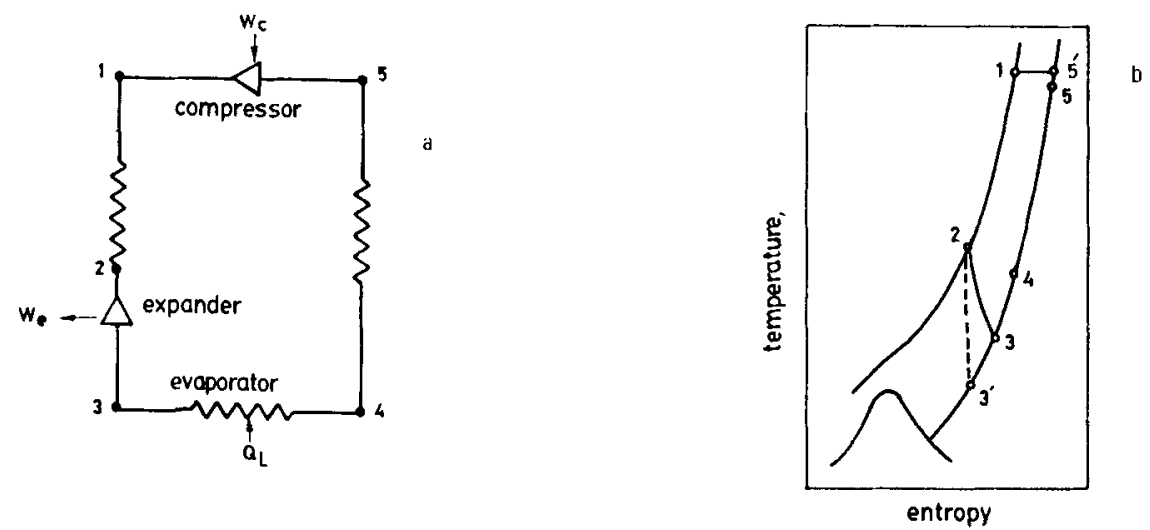

Figure 5a. Modified Brayton cycle refrigerator. b. $T-S$ diagram for modified Brayton cycle.

heat exchanger (HE), $\left(2-3^{\prime}\right)$ is isentropic expansion in the expander, $\left(3^{\prime}-4\right)$ is the supply of refrigeration and $\left(4-5^{\prime}\right)$ is the warming back in the heat exchanger. However, in the actual case, compression will be from 5 to 1 since there will always be a temperature difference at the warm end of the HE, since it is not $100 \%$ efficient. The expansion will be from 2 to 3 rather than 2-3' since the expander is normally only $60-70 \%$ efficient. Therefore, the actual refrigeration available will be $\left(h_{4}-h_{3}\right)$ rather than $\left(h_{4}-h_{3}\right)$. Specific power is given by

$$
W_{c} / Q_{L}=-R \cdot T_{1} \cdot \ln \left(P_{2} / P_{1}\right) /\left(h_{4}-h_{3}\right) \text {. }
$$

It should be noted that the modified Brayton cycle does not produce refrigeration at a single temperature but does so over a range of temperatures. Performance of this cycle is extensively studied by Muhlenhaupt \& Strobridge (1968), with nitrogen, hydrogen and helium as the working fluids. They have drawn graphs which readily give the values of $\left(W_{c} / Q\right)$ against high pressure for various values of expander efficiencies and heat exchanger warm end temperature differences $\Delta T$. Here an ambient temperature of $300 \mathrm{~K}$ and a low pressure of $1 \mathrm{~atm}$ are assumed. For example, at a refrigeration temperature of $20 \mathrm{~K}$ and $70 \%$ expander efficiency, increasing the value of $\Delta T$ from $2 \mathrm{~K}$ to $4 \mathrm{~K}$ increases the compressor power by $27 \%$ to produce the same amount of refrigeration. Other information such as expander power output, flow rate required etc. is also available in those graphs.

A cold gas refrigeration system of this type has been used by the Linde Co., Tonawada, in providing refrigeration for the cryopanels of space-simulation chambers (Vance \& Duke 1962).

3.2e Stirling cycle liquefiers/refrigerators: The Stirling cycle, invented by a Scottish minister, Robert Stirling, in 1816 was used in a hot air engine. In 1834 John Herschel suggested that this engine could be used as a refrigerator. However, the Philips company of Eindhoven, Netherlands, virtually rediscovered this cycle, and Kohler and coworkers succeeded in 1954 in building a low-temperature refrigerator, air/nitrogen liquefier using this cycle (Kohler \& Jonker 1954; Vander Ster \& Kohler 1958). 
A schematic diagram of the Stirling cycle refrigerator and the cycle on the $P \cdot V$ and $T-S$ diagrams are shown in figure 6 (Croft 1971). Essentially, it consists of a piston and a displacer moving inside a cylinder, thus forming two volumes: a compression volume and an expansion volume. These two volumes are connected by a very efficient ( $\varepsilon>99 \%$ ) heat exchanger called "regenerator". Working of the ideal Stirling cycle is as follows:

(i) displacer being on top, piston moves up compressing the gas isothermally (process 1-2). Heat of compression is removed in a water cooler;

(ii) displacer now moves down, displacing the gas at constant volume, through the regenerator (process 2-3). The regenerator which is cold due to the previous cycle; cools the gas;

(iii) now, both the displacer and the piston move down. Gas in the expansion volume expands doing work and then cools. This supplies the refrigeration load at constant temperature (process 3-4);

(iv) now, the piston being stationary, the displacer moves up, thus displacing the cold gas through the regenerator (process 4-1) to the compression volume. The
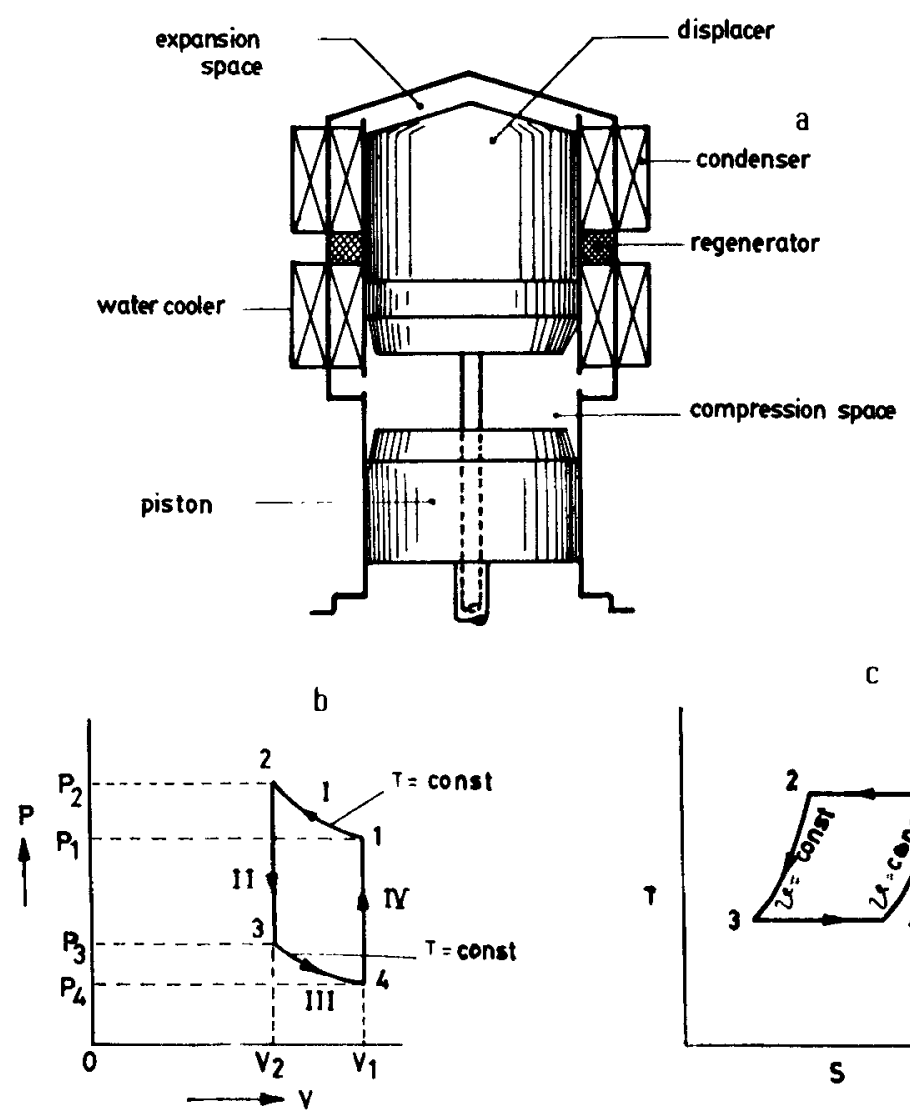

C

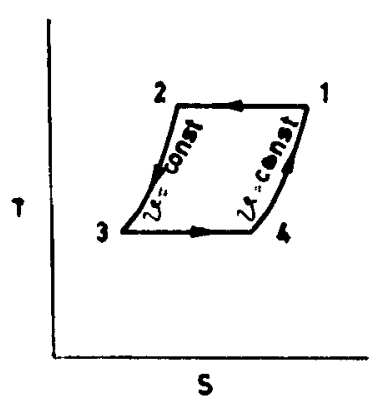

Figure 6a. Philips Stirling cycle cryogenerator. b. $P-V$ diagram for Stirling cycle. e. $T-S$ diagram for Stirling cycle. 
cold gas deposits its "cold" in the regenerator and this is used to precool the next batch of gas in the subsequent cycle;

(v) The piston moves up and the cycle repeats.

From the $T-S$ diagram,

refrigerating effect

$$
Q_{L}=m \cdot T_{3} \cdot\left(S_{4}-S_{3}\right),
$$

heat rejected

$$
Q_{R}=m \cdot T_{1} \cdot\left(S_{2}-S_{1}\right),
$$

where $m$ is the mass of gas in the refrigerator cylinder.

By the I law,

$$
W_{\text {net }}=Q_{L}+Q_{R}
$$

and the specific power is given by

$$
-W_{\text {net }} / Q_{L}=\left[T_{1} \cdot\left(S_{1}-S_{2}\right) /\left(S_{4}-S_{3}\right)-T_{3}\right] / T_{3} .
$$

For a perfect gas,

$$
\begin{aligned}
\left(S_{1}-S_{2}\right) & =c_{v} \cdot \ln \left(T_{1} / T_{2}\right)+R \cdot \ln \left(v_{1} / v_{2}\right) \\
& =R \cdot \ln \left(v_{1} / v_{2}\right)=R \cdot \ln \left(v_{4} / v_{3}\right)
\end{aligned}
$$

since $T_{1}=T_{2}, v_{1}=v_{4}$ and $v_{2}=v_{3}$, where $v$ is the specific volume of gas. Thus

$$
\left(S_{1}-S_{2}\right)=\left(S_{4}-S_{3}\right)
$$

and, we get,

$$
\left(-W_{\text {nct }} / Q_{L}\right)=\left(T_{1}-T_{3}\right) / T_{3} \text { for a perfect gas. }
$$

It may be noted that this is equal to the $W / Q$ of the Carnot cycle. Thus, the ideal Stirling cycle has an FOM equal to 1 . However, for the practical cycle, there are mechanical losses in the drive unit, losses due to finite pressure and finite temperature drops in the regenerator, losses due to finite temperature differences during heat absorption and rejection - all of which reduce the value of FOM. Figure of merit of the Philips refrigerator is about $30 \%$ at about $80 \mathrm{~K}$. Still, this value is quite high as compared to other cycles, as can be seen from the Nesselmann graph shown in figure 7 (Haselden 1971). Walker (1973) has given a detailed theoretical analysis of the Stirling cycle. He has also given consolidated design charts which can be used for optimisation of design parameters.

Salient features of the Stirling cycle may be summarised as follows:

(i) Theoretical coefficient of performance $(\mathrm{COP}=Q / W)$ of an ideal Stirling cycle is equal to that of the Carnot cycle;

(ii) higher figure of merit as compared to other cycles;

(iii) no valves, hence, fewer irreversible losses. This results in a higher thermodynamic efficiency Also because of this, a higher speed of operation (1500 r.p.m.) is possible, thus giving a smaller value of weight/refrigeration produced ratio. This is important in space applications;

(iv) closed cycle operation using hydrogen or helium gas;

(v) use of very efficient regenerators $(\varepsilon>99 \%)$; 


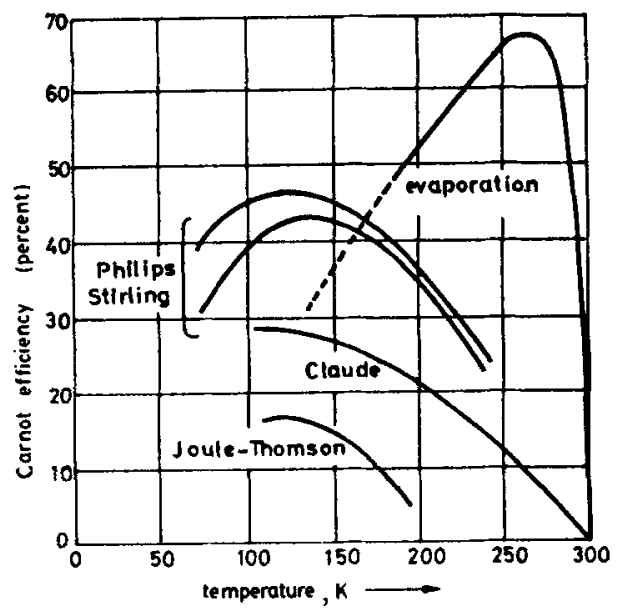

Fgure 7. Nesselmann graph.

(vi) very compact, since there is no separate compressor;

(vii) ease of multistaging for attaining lower temperatures. There will be only one compression piston and one displacer, but the displacer diameter is reduced in one or two stages so that additional expansion volumes are formed. These volumes are connected to each other by additional regenerators. Three-, four- and five-stage Stirling cycle cryorefrigerators based on this principle are also built (Zimmermann \& Radebaugh 1978, pp. 59-70; Zimmermann \& Sullivan 1982).

Laboratory $\mathrm{LN}_{2}$ plants built by Philips $(6 \mathrm{l} / \mathrm{hr}$ and $30 \mathrm{l} / \mathrm{hr}$ capacity) have become quite popular. Philips have also built other liquefiers/cryogenerators for hydrogen, helium etc. using this cycle. Details about some of the Philips models are given in table 9 (Product Bulletin 1979a).

Because of its special features, the Stirling cycle has been seriously considered for space-borne refrigeration systems, for example, to cool infrared detectors and other electronic devices. Donabedian (1972) has compiled the performances of such miniature Stirling cycle refrigerators manufactured by Philips, Malaker Corporation, Hughes Aircraft Co., and Kinergetics. As an example, the "cryogem" model of Philips (USA), attains $25 \mathrm{~K}$ in three minutes and provides 1 Watt of refrigeration at this temperature; input power is $475 \mathrm{~W}$ and weight is only $9 \mathrm{~kg}$ (Daniels \& du Pre 1971). Notable modifications in this version as compared to larger models are: the regenerator being inside the displacer, a two-stage expansion, the drive motor being inside the crankcase, reinforced teflon bearings and seals. Gasser et al (1981, pp. 103-115) have reported on a 3-5 year lifetime Stirling cycle refrigerator for space applications. Here, the machine comprises a compressor section and an expansion section bolted together; each section has its own magnetic bearings, linear motor, displacement transducer (LVDT) and displacement volume. Phase angle and relative movements of piston and displacer are electronically controlled using the signals from the LVDT.

One drawback of conventional Stirling cycle machines is the wear of seals and the contamination of working gas by the lubricating oil used. This reduces the life time. With the idea of getting high MTBF, particularly for military applications, split-Stirling cycle refrigerators have been developed for cooling IR detectors and 


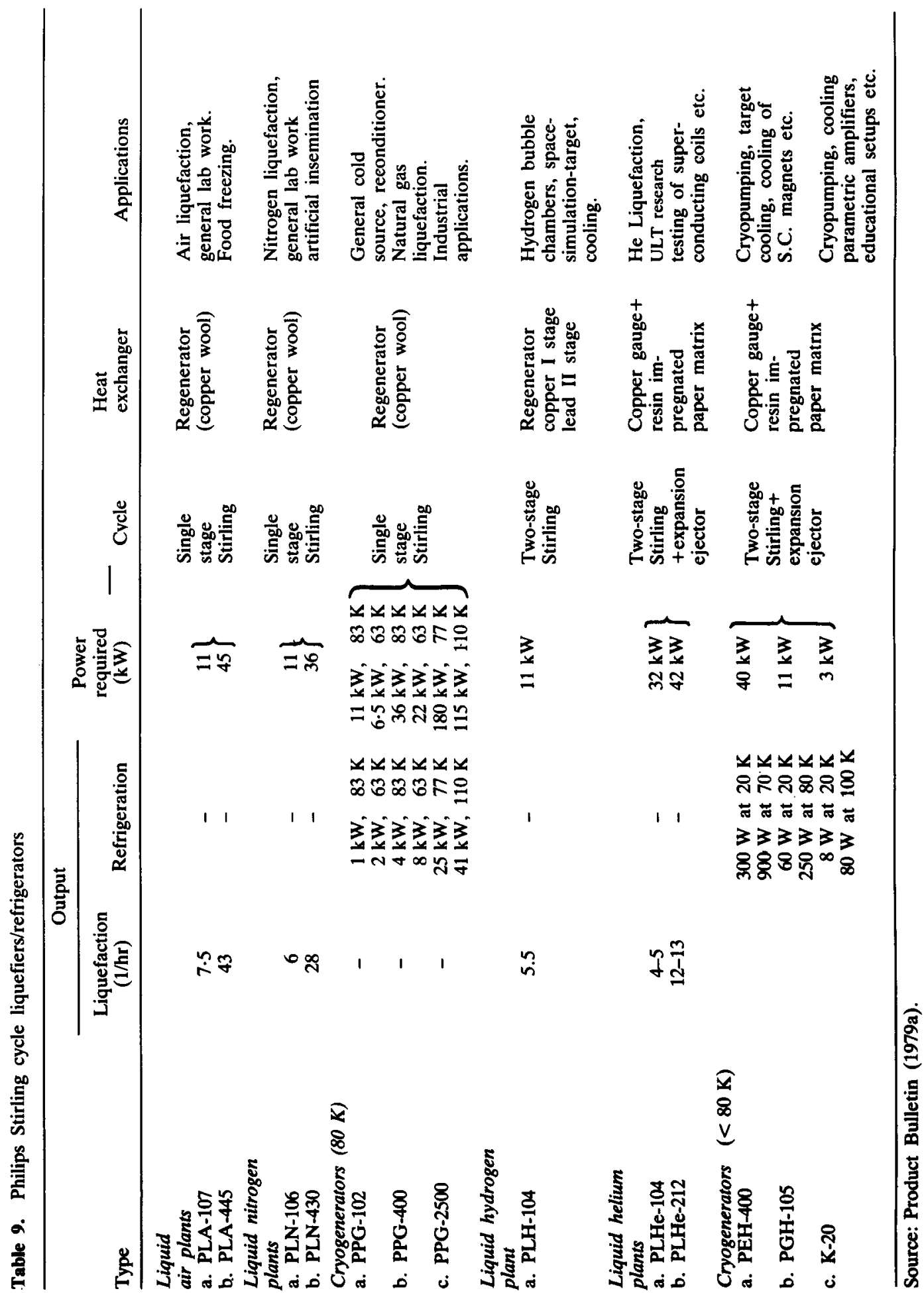


are described by Lehrefeld (1983). Here, the compressor portion is isolated from the displacer portion. The piston is directly reciprocated by supplying an a.c. waveform to the coil of an electric motor. The piston, in turn, drives the free displacer of the cold finger by fluidic coupling. A mechanical spring is affixed to the displacer and housing. This forms a spring-mass system which ensures the proper relative movements of the piston and displacer. Clearance type of seals are used. Cooling capacity is $1 \mathrm{~W}$ at $80 \mathrm{~K}$ and MTBF is over $2500 \mathrm{hrs}$. In fact, this is a modified version of the commercially produced Philips model MC- 80 free displacer Stirling refrigerator described earlier by Haarhuis (1978).. L'Air Liquide of France also commercially produce split-Stirling refrigerators to meet military specifications. Here, a typical refrigeration capacity is $1 \mathrm{~W}(\max )$ at $76 \mathrm{~K}$. The compressor portion weighs about $2.5 \mathrm{~kg}$ and the cold finger weighs about $80 \mathrm{~g}$. Maximum power absorbed at ambient temperature is $60 \mathrm{~W}$ (Product Bulletin 1983b).

Medium-size liquid nitrogen plants and liquid helium plants produced commercially, normally use any one of the cycles mentioned above in $\$ \$ 3.2 \mathrm{~b}$ to $3.2 \mathrm{e}$. Tables 10 and 11 give typical examples of some medium capacity liquid nitrogen plants available indigenously, and from foreign sources, respectively. Table 12 gives details about some of the standard models of liquid helium plants available commercially. It should be noted that these tables are only illustrative and do not cover all the available models from all the sources.

3.2f Gifford-McMahon cycle cryorefrigerators: Gifford \& McMahon (1960a, b, c) (G-M), reported on two novel refrigeration systems which have found ready applications in small capacity cryorefrigerators. Both the systems are basically similar; one has a single expansion volume whereas the other has two volumes. Methods of computing the performance of the G-M cycle are reported by several authors (Gifford \& McMahon 1960a, b, c; Gifford 1961, 1966; Gifford \& Hoffman 1961; Hrycak 1963; Barron 1966; Ackermann \& Gifford 1971).

(i) Single volume G-M cycle cryorefrigerator: A schematic diagram of the system and the $P-V$ diagram of the cycle are shown in figure 8 . It basically consists of a

Table 10. Liquid nitrogen plants from indigenous suppliers

\begin{tabular}{|c|c|c|c|c|c|c|c|}
\hline \multirow[b]{2}{*}{ Name of Firm } & \multicolumn{3}{|c|}{ B.H.P.V. ${ }^{+}$} & \multicolumn{2}{|c|}{ Indian Oxygen } & \multicolumn{2}{|c|}{ I.C.C.P. ${ }^{+}$} \\
\hline & 1 & 2 & 3 & 1 & 2 & 1 & 2 \\
\hline Capacity $(\mathbf{l} / \mathbf{h r})$ & 20 & $40 / 45$ & 200 & $25 / 30$ & 140 & $25 / 30$ & 100 \\
\hline Cycle & Linde & Linde & Heylandt & Claude & Heylandt & Linde & Linde \\
\hline Pressure (atm) & 180 & 200 & 90 & 210 & 200 & 200 & 200 \\
\hline $\begin{array}{l}\text { Expansion engine } / \\
\text { turbine }\end{array}$ & - & - & $\begin{array}{c}\text { Expansion } \\
\text { engine }\end{array}$ & $\begin{array}{l}\text { Expan- } \\
\text { sion } \\
\text { engine }\end{array}$ & $\begin{array}{l}\text { Expan- } \\
\text { sion } \\
\text { engine }\end{array}$ & - & - \\
\hline Heat exchanger & $\begin{array}{l}\text { Coiled } \\
\text { tube }\end{array}$ & $\begin{array}{l}\text { Coiled } \\
\text { tube }\end{array}$ & $\begin{array}{l}\text { Coiled } \\
\text { tube }\end{array}$ & $\begin{array}{l}\text { Coiled } \\
\text { tube }\end{array}$ & $\begin{array}{l}\text { Coiled } \\
\text { tube }\end{array}$ & Shell & \& Tube \\
\hline Power (kW) & 90 & 170 (approx.) & 310 & 75 & 280 & 90 & $\begin{array}{c}300 \\
\text { (approx.) }\end{array}$ \\
\hline $\begin{array}{l}\text { Water }\left(\mathrm{m}^{3} / \mathrm{hr}\right) \\
\text { Space }\end{array}$ & $\frac{22}{20 \times 9 \times 7 \mathrm{~m}^{3}}$ & $\frac{20}{12.5 \times 9 \times 7 \mathrm{~m}^{3}}$ & $\begin{array}{c}35 \\
1.5 \times 16 \times 9 \mathrm{~m}^{3}\end{array}$ & * & $260 \mathrm{~m}^{2}$ & $\begin{array}{c}18 \\
80 \mathrm{~m}^{2}\end{array}$ & * \\
\hline
\end{tabular}

Source: Product Bulletins of companies concerned; ${ }^{\dagger}$ Bharat Heavy Plates and Vessels, Vishakhapatnam;

+ The Industrial Cryogenic and Chemical Plants Ltd., Calcutta; * Data not available. 

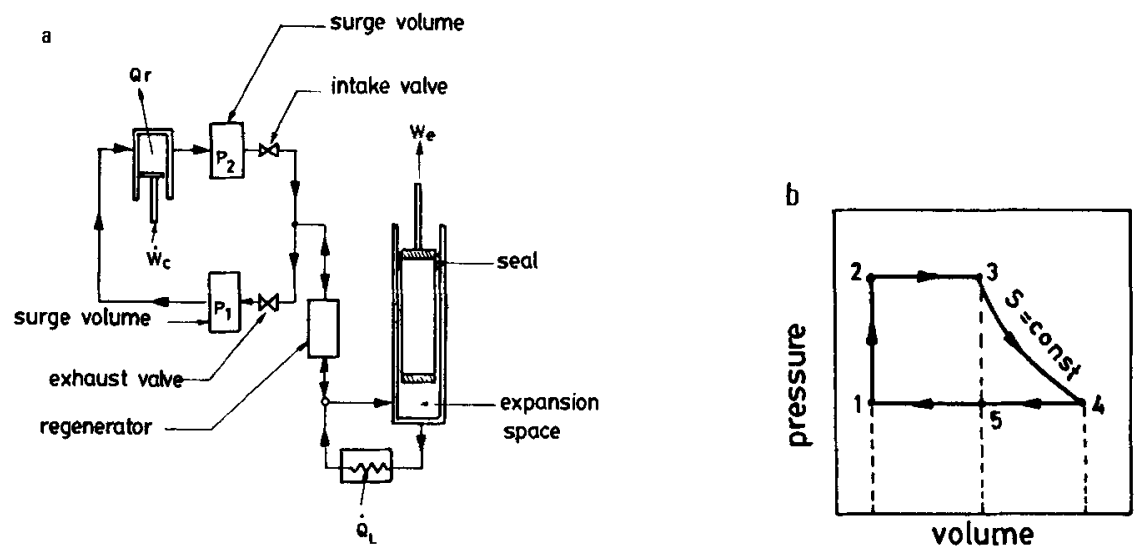

Figure 8a. Single volume G-M cycle refrigerator. b. $P-V$ diagram for single volume $G-M$ cycle refrigerator.

of low thermal conductivity such as micarta. The heart of the system is the regenerator made of a stack of punched copper wire-screens. The sequence of operation is as follows:

Process 1-2: With the piston at the bottom end of the stroke, the inlet valve is opened. The gas, while flowing through the regenerator, gets cooled if the regenerator is already cold due to the previous cycle. System pressure increases from low pressure $P_{1}$ to high pressure $P_{2}$.

Process 2-3: With the inlet valve still open, the piston moves up so that additional volume of gas $\left(V_{3}-V_{2}\right)$ is drawn into the expansion volume through the regenerator.

Process 3-4: Now, the inlet valve is closed and the gas in the volume is expanded isentropically to pressure $P_{1}$, doing work on the piston. Therefore, the temperature of the gas falls.

Table 11. Liquid nitrogen plants from foreign suppliers

\begin{tabular}{|c|c|c|c|c|c|c|c|}
\hline \multirow[b]{2}{*}{ Name of Firm } & \multirow{2}{*}{$\begin{array}{l}\text { BOC } \\
\text { (UK) }\end{array}$} & \multirow{2}{*}{$\begin{array}{c}\text { L'Air } \\
\text { Liquide } \\
\text { (France) }\end{array}$} & \multicolumn{2}{|c|}{ Philips (Holland) } & \multirow{2}{*}{$\begin{array}{c}\text { Sulzer } \\
\text { (UK) }\end{array}$} & \multicolumn{2}{|c|}{$\begin{array}{c}\text { Superior Air Products } \\
\cdot \text { (USA) }\end{array}$} \\
\hline & & & 1 & 2 & & 1 & 2 \\
\hline Capacity (1/hr) & 14 & 50 & 30 & 90 & 24 & 25 & 100 \\
\hline Cycle & Claude & Claude & Stirling & Stirling & Claude & Linde & Linde \\
\hline Pressure (atm) & $10-15$ & 13 & Air at ambie & ent pressure & 10 & 170 & 200 \\
\hline $\begin{array}{l}\text { Expansion engine/ } \\
\text { turbine }\end{array}$ & Turbine & Turbine & - & - & Turbine & - & - \\
\hline Heat exchanger & Plate-fin & Plate-fin & Regenerator & Regenerator & Plate-fin & $\begin{array}{c}\text { Coiled } \\
\text { tube }\end{array}$ & $\begin{array}{c}\text { Coiled } \\
\text { tube }\end{array}$ \\
\hline Power $(\mathrm{kW})$ & 29 & 80 & 40 & $40 \times 3$ & 40 & 57 & 112 \\
\hline Water $\left(\mathrm{m}^{3} / \mathrm{hr}\right)$ & 1.25 & 11 & 3 & $3 \times 3$ & 2 & $5 \cdot 25$ & 12 \\
\hline Space & $7 \mathrm{~m}^{2}$ & $30 \mathrm{~m}^{2}$ & $4.5 \times 2.7 \times 3 \mathrm{~m}^{3}$ & $3-45 m^{2}$ & $4 \mathrm{~m}^{2}$ & - & - \\
\hline
\end{tabular}

Source: Product Bulletins of the companies. 
Process 4-5: Exhaust valve is now opened, and the piston moves down, forcing the cold gas through the load.

Process 5-1: Finally, the gas passes out through the regenerator and gets warmed.

The refrigeration effect is

$$
Q_{L}=m_{e} \cdot\left(h_{5}-h_{4}\right),
$$

where $m_{e}$ is the mass of gas expanded in the cylinder. Work of isothermal compression,

$$
W_{c}=-m \cdot R \cdot T_{2} \cdot \ln \left(P_{2} / P_{1}\right),
$$

where $m$ is the mass of gas compressed in the compressor. This assumes that the work output during expansion is not utilised in the compression process. If it is utilised, then the net work requirement will be reduced by this amount.

$$
W_{e}=m_{e} \cdot\left(h_{3}-h_{4}\right) \text {. }
$$

The factor $W_{c} / Q_{L}$ is calculated from these two equations.

(ii) Double volume $G-M$ cycle cryorefrigerator (low temperature heat pump): The schematic diagram of the system and the $P-V$ diagram are shown in figure 9 . It consists of a thin-walled stainless steel cylinder inside which a displacer made of a low thermal conductivity material, such as micarta, moves. The two volumes thus formed are connected to each other through a regenerator. Gas admission and exhaust are through valves as shown. This is a "no work" cycle since there is no net work output from the shaft. Instead, it operates as a heat pump, pumping the heat from lower volume to upper volume (Gifford and Withjack 1969). Sequence of operation is as follows:

Process 1-2: The displacer being at the bottom-most position and the exhaust valve being closed, the inlet valve is opened. Pressure in the upper expansion space and regenerator increases from $P_{1}$ to $P_{2}$.

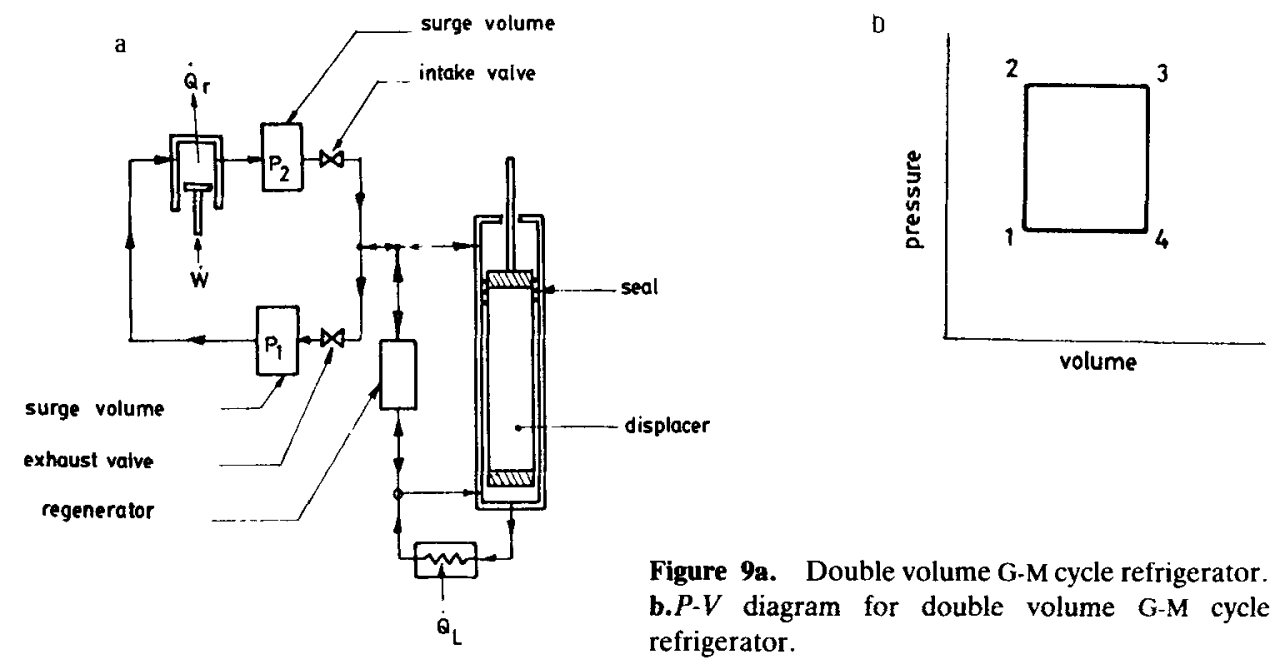




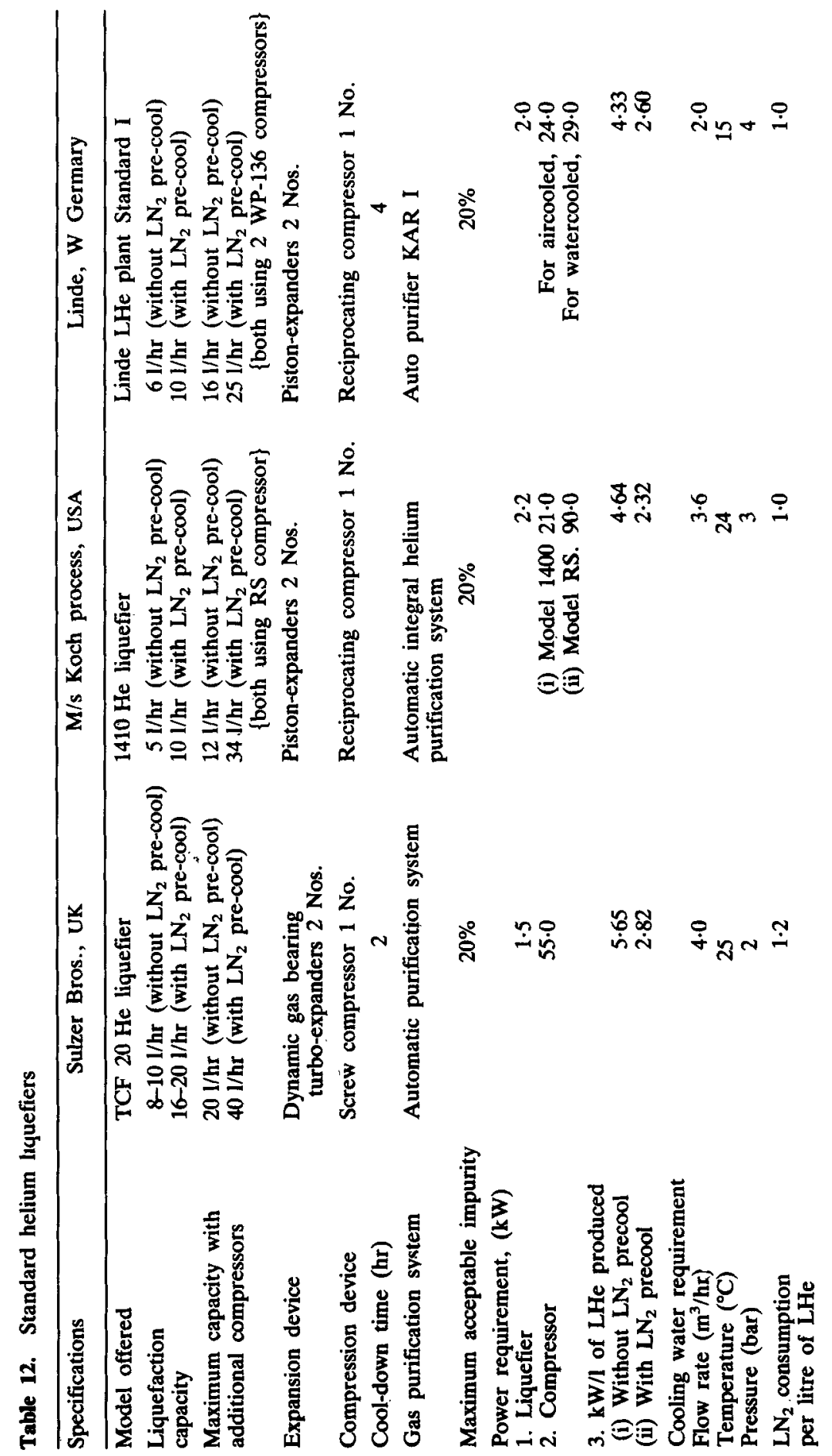




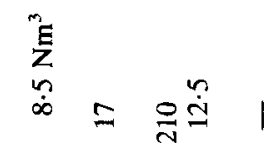

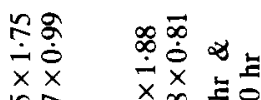

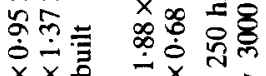

$$
\begin{aligned}
& \text { 啇完 }
\end{aligned}
$$

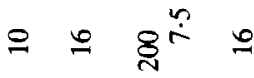
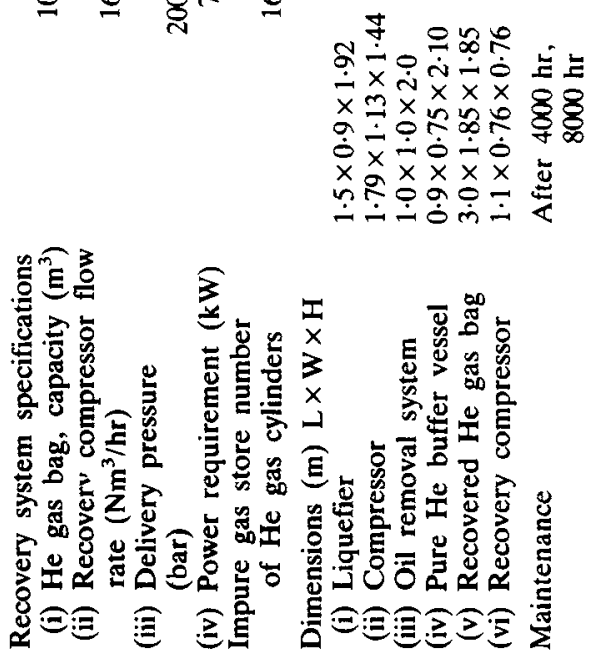
Process 2-3: The inlet valve still being open, the displacer moves up, thus displacing the gas to the lower expansion space through the regenerator. If the regenerator is already cold due to the previous cycle, the gas gets cooled in the regenerator and some more gas flows in through the inlet valve.

Process 3-4: When the displacer reaches the top of its stroke, the inlet valve is closed and the exhaust valve is opened. Now the gas in the expansion volume undergoes "Joule expansion"-i.e. the gas remaining in the volume after expansion has done work in pushing the gas that has gone out - thus producing cooling.

Process 4-5: Now the displacer moves down, with the exhaust valve still being open. The cold gas remaining in the lower expansion volume moves out, thus providing refrigeration.

Process 5-1: After providing the refrigeration, the gas enters the regenerator and gets warmed as it flows out, depositing its 'cold' in the regenerator. This will be used in precooling the next batch of gas when the cycle repeats.

G-M cycle cryorefrigerators providing refrigeration at $80 \mathrm{~K}$ in a single stage and at $30 \mathrm{~K}$ and $15 \mathrm{~K}$ in the second and third stages have been built (Gifford 1961). The three-stage cryorefrigerator was used to precool a separate J-T stream of high pressure helium in a small helium liquefier producing about $0.5 \mathrm{l} / \mathrm{hr}$ of liquid helium.

Salient features of the G-M cycle machines are summarised below:

(i) Highly reliable - MTBF of the order of $10,000 \mathrm{hr}$, since there is less wear and tear of seals and other mechanisms due to slower running speeds $(60-150 \mathrm{rpm})$.

(ii) Compressor portion is isolated-unlike in the Stirling machines - this minimises vibration and increases convenience and flexibility.

(iii) Valves and seals are at room temperature.

(iv) Simpler driving mechanism since the same need be designed only to take care of the friction of the seals and the small pressure differential across the regenerator (in the double volume system).

(v) Clearance between cylinder and displacer is not as critical as in other machines. Clearance of the order of 0.003 in to 0.010 in $(0.075 \mathrm{~mm}$ to $0.25 \mathrm{~mm})$ is sufficient.

(vi) Use of highly efficient thermal regenerators which are easy to build.

(vii) Less sensitive to gas impurities because during the reverse flow in each cycle the condensed impurities get blown out.

(viii) Ease of multistaging. Addition of one more stage involves only addition of an expansion volume and a regenerator. The same inlet and exhaust valves as at room temperature are used. Schematic of a three-stage G-M cycle refrigerator is shown in figure 10. Stuart et al (1971) have described the performance of a $4 \mathrm{~K}$ refrigerator wherein they use a coaxial three-stage G-M cycle machine to precool the J-T stream. Another three-stage machine has produced $6.5 \mathrm{~K}$ in the third stage (Stuart et al 1970).

The efficiencies of these machines are quite low. For example, for practical $4.2 \mathrm{~K}$ refrigerators, the figure of merit (or percent Carnot) of G-M cycle machines varies from about $1 \%$ to $4 \%$ as shown by Strobridge \& Chelton (1967). Still, G-M cycle refrigerators have become quite popular because of their simplicity and high 


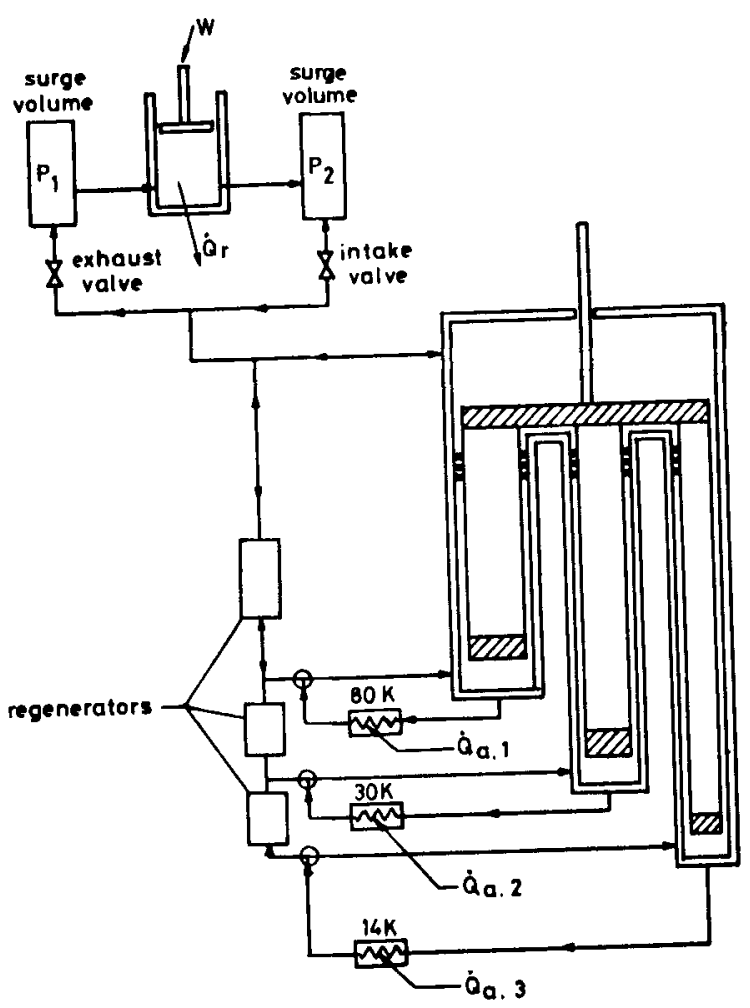

Figure 10. Schematic diagram of three-stage G-M cycle refrigerator.

reliability. A detailed survey of commercially available cryogenic refrigerators given by Crawford (1970), contains data on G-M cycle refrigerators also.

Some of the areas of application of these small capacity G-M cycle refrigerators are the following: (i) IR detector cooling; (ii) cooling of parametric amplifiers; (iii) Mossbauer spectroscopy; (iv) field ion microscopy; (v) cryopumping; (vi) cryobiology; (vii) cold trap in high vacuum systems.

$3.2 \mathrm{~g}$ Solvay cycle cryorefrigerators: The Solvay cycle is a variation of the double volume G-M cycle. Here, instead of having a separate motor and linkage drive for the displacer and the valves, the motion of the displacer is obtained by having a surge volume connected to the expansion volume through an orifice and by making use of a rotary valve for gas inlet and exhaust. The advantages of the G-M cycle, such as the valve operating at room temperature, use of a regenerator, moderate speeds etc., are still retained. Longsworth (1970) has described a Solvay cycle cryorefrigerator. A schematic diagram of the system and the cycle on the $P-V$ diagram are shown in figure 11.

The system works as follows:

(i) With the displacer at the cold end and the warm end volume at pressure $\boldsymbol{P}_{i}$ the inlet valve is opened. Gas gets cooled as it flows through the regenerator and pushes the displacer rapidly to the warm end, increasing the warm end volume pressure to $P_{H}$. 

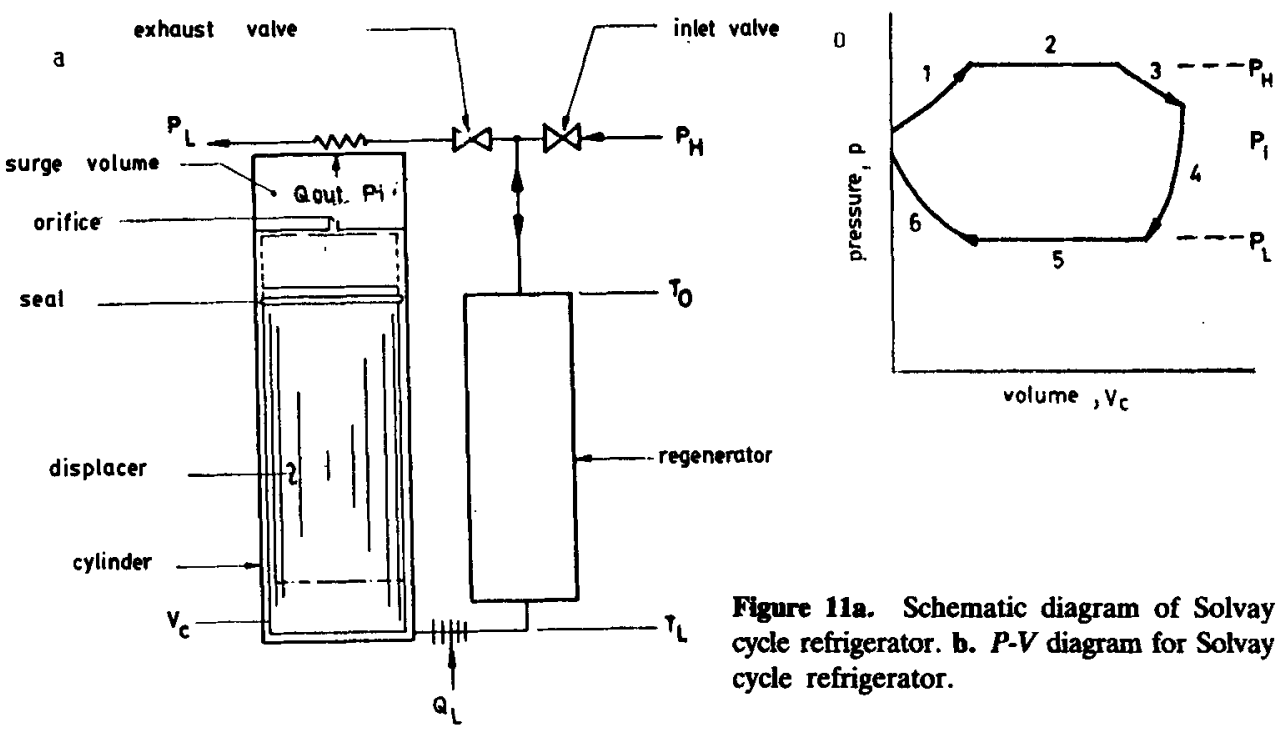

(ii) Gas bleeds through the orifice to the surge volume and the displacer moves at constant velocity towards the warm end.

(iii) Before the displacer reaches the warm end, the inlet valve is closed and gas in cold volume expands to $P_{i}$.

(iv) The exhaust valve is opened causing the gas in the cold volume to expand During this phase, warm volume pressure drops to $P_{L}$ and displacer moves towards the cold end.

(v) Gas continues to bleed from the surge volume and the displacer moves towards the cold end at constant velocity. Cold gas flows out through the regenerator.

(vi) The exhaust valve is shut before the displacer hits the bottom, decelerating the displacer. Gas pressure in the warm volume increases to $P_{i}$. The cycle is then repeated.

This refrigerator, reported by Longsworth, had an operating speed of 144 cycles $/ \mathrm{min}$ with the pressure $320 / 115 \mathrm{psig}\left(2.25 \times 10^{5} / 0.81 \times 10^{5} \mathrm{~kg} / \mathrm{m}^{2}\right)$. The measured value of heat load was $20 \mathrm{~W}$ at $77 \mathrm{~K}$ which was $49 \%$ of the refrigeration produced as determined from the $P-V$ diagram.

Cryogenic Technology Inc., (CTI), USA produce cryorefrigerators based on the G-M cycle and Air Products \& Chemicals Inc., USA, produce refrigerators based on the Solvay cycle. Details about some of their models are given in table 13. Table 14 shows some details about the refrigerator operated type of cryopumps based on these cycles which have become very popular for applications in the fields of sputtering, optical coating, UHV, space simulation etc.

3.2h Free displacer cryorefrigerator: This is also a displacer type of refrigerator similar to Stirling or G-M cycle refrigerators. However, here there is a built-in compressor and the displacer is "free" or floating inside the cylinder. The movement of the displacer is obtained by pressure fluctuations caused in the 


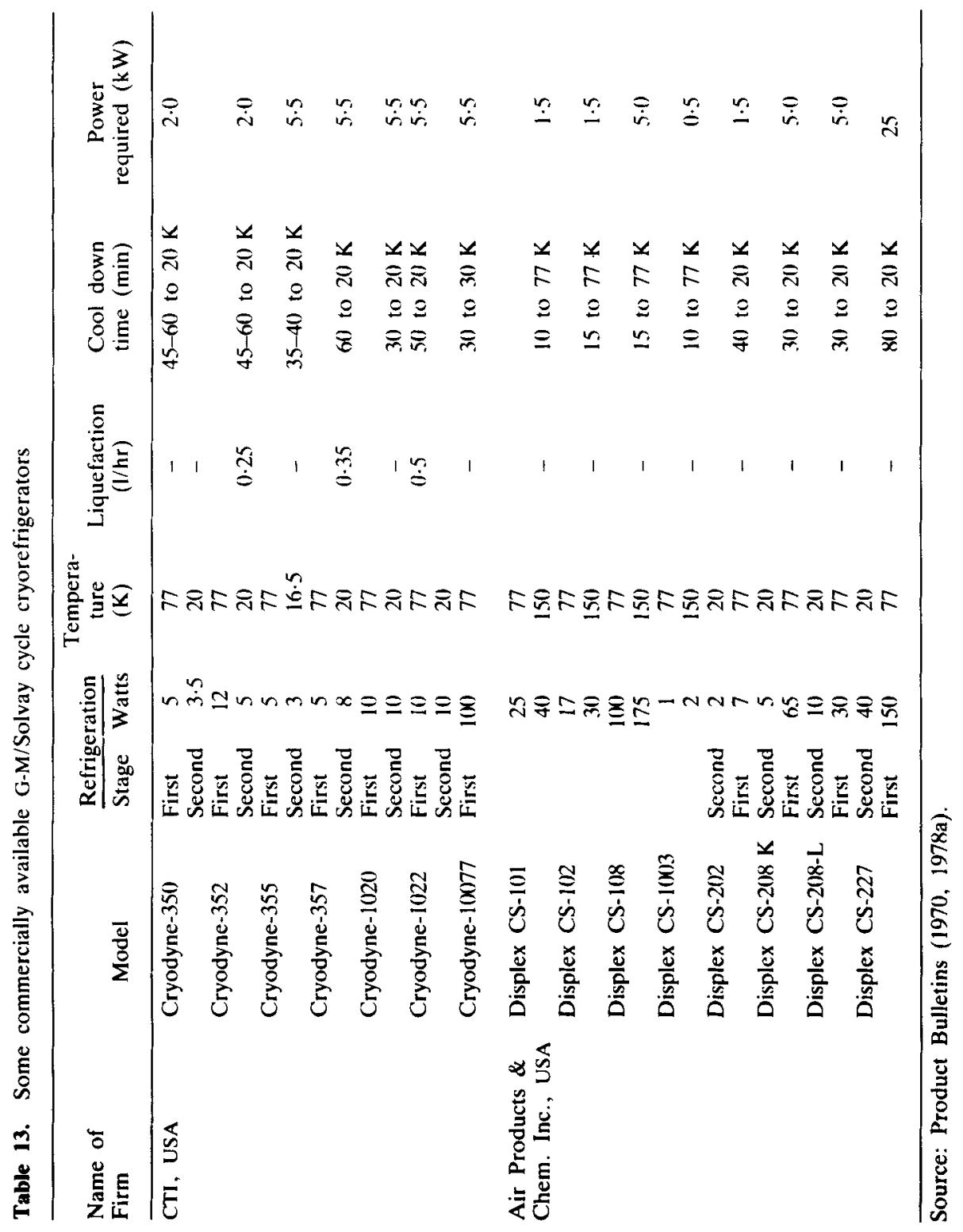


Table 14. Some commercially available cryopumps based on G-M/Solvay cycle cryorefrigerators

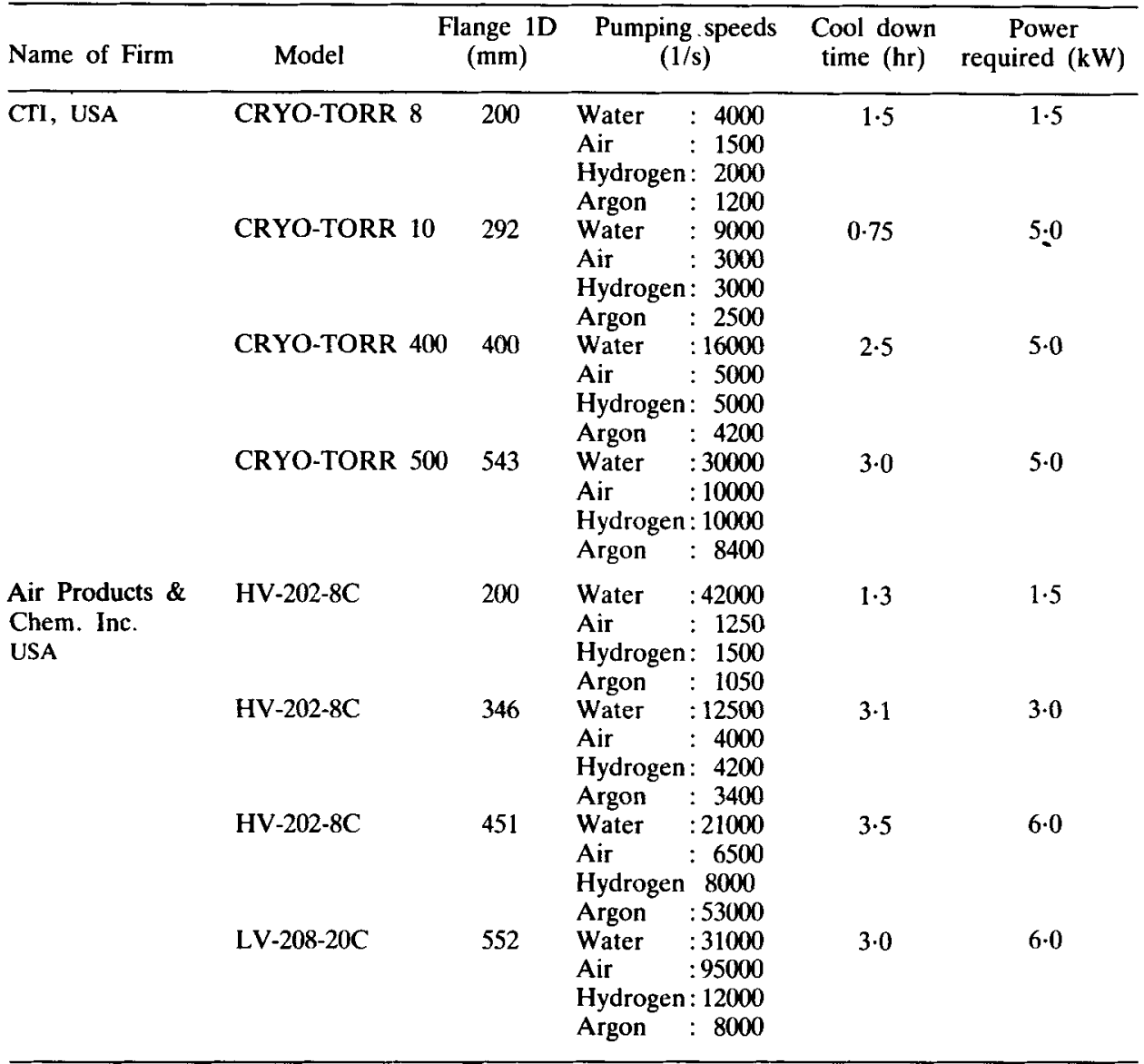

Source: Product Bulletins (1970, 1978a)

adjoining compression volume. Gifford \& Withjack (1969) developed a cryorefrigerator operating on this cycle and giving about $9 \mathrm{~W}$ of refrigeration at $80 \mathrm{~K}$. Figure 12 shows a schematic diagram of the refrigerator and the $P-V$ diagram for the cycle. In the figure shown, the displacer has got a "stopper" at the cold end which decides the minimum volume at that end when the displacer is at the top-most position. The working of the system is as follows:

(i) The displacer is at the bottom-most position. The piston moves up increasing the pressure isentropically. The displacer moves up as it is free to move.

(ii) The displacer moves to the top-most position, this being limited by the stopper at its top. Further movement of the piston causes the pressure to rise and more gas is transferred through the regenerator from volume 1 to volume 2 .

(iii) Now the piston moves down. Pressure is decreased in both the chambers isentropically and the displacer moves down.

(iv) The displacer comes to the bottom-most position; piston continues to move down causing the pressure to decrease further. Gas flows from chamber 2 to chamber 1 through the regenerator.

Refrigeration available is equal to the work leaving the chamber 2. Pressure 
(a)
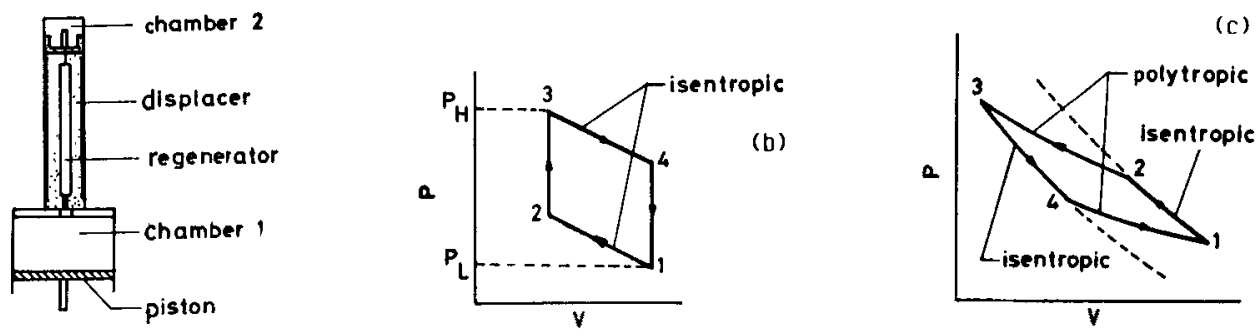

Figure 12a. Schematic diagram of free displacer cryorefrigerator. b. $P-V$ diagram for chamber 2. c. $P$-V diagram for chamber 1 .

reached at the end of the isentropoic compression should be less than $P_{H}$ to provide the refrigerating effect since it is necessary that a closed cycle should be formed on the $P$ - $V$ diagram for volume 2 .

Jain (1980) reported about a free displacer cryorefrigerator which gave a lowest temperature of $113 \mathrm{~K}$ using nitrogen as working gas at a pressure of $10 \mathrm{~atm}$. Speed of operation was $280 \mathrm{rpm}$. The refrigeration load was about $0.9 \mathrm{~W}$ at $120 \mathrm{~K}$. He modified an existing compressor into a non-lubricated compressor by using suitable PTFE seals and used this in conjunction with the free-displacer cold end.

3.2i Vuilleumier cycle cryorefrigerator: The Vuilleumier (V-M) cycle, patented by Vuilleumier in 1918, is known as a "hot-gas refrigerator" and efforts have been made to explore the practical possibilities of this cycle (Rule \& Qvale 1968). It may be recalled that in the Stirling cycle, refrigeration is produced by the relative variations of pressures and volumes of expansion and compression spaces, obtained with the help of suitably phased mechanical piston and displacer. In the V-M cycle, the mechanical compressor is replaced by a "Thermal compressor".

A schematic diagram of the V-M cycle refrigerator is shown in figure 13 (Daniels \& du Pre 1971).

It consists of two displacers, containing regenerators within them, moving inside two interconnected cylinders with a phase difference of about $90^{\circ}$. A small electric motor drives these displacers. There are no valves. Cylinder B is kept at a high temperature (about $1000 \mathrm{~K}$ ). When the hot displacer is 'down' much of the helium is in the hot area and the average temperature - and therefore, the average pressure in the working space - is high. When the hot displacer is 'up', very little helium is in the hot area and the average helium temperature, and therefore the average pressure, is low. Thus, when the hot displacer moves up and down in correct phase relationship with the cold displacer, pressure and volume variations are produced in the expansion space as in the case of the Stirling cycle machine and refrigeration is produced.

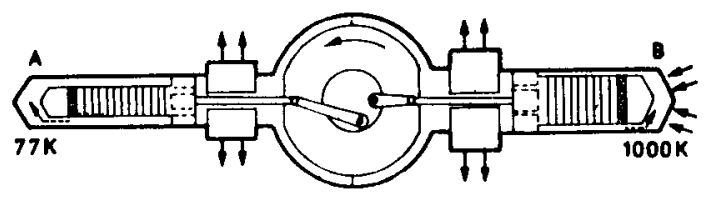

Figure 13. Schematic diagram of Vuilleumier cycle refrigerator. 
Salient features of the $\mathrm{V}-\mathrm{M}$ cycle refrigerator are:

(i) Produces cold directly from heat. So, any heat source can be used.

(ii) Power required to run the displacers is small.

(iii) Lends itself to miniaturisation; therefore, is actively considered for spaceborne and military applications.

(iv) Quiet and vibration-free.

(v) One disadvantage is the limitation of high temperatures since above $1000 \mathrm{~K}$, material selection becomes a problem.

(vi) Another limitation is the low pressure ratio-of the order of 1.4 , as compared to 2.5 in the case of Stirling cycle machines.

Pitcher \& du Pre (1970) have described a miniature V-M cycle refrigerator giving about $2 \mathrm{~W}$ at $77 \mathrm{~K}$. Helium gas at $40 \mathrm{~atm}$ pressure was used. Rotation was at $600 \mathrm{rpm}$ and motor power required was $6 \mathrm{~W}$. Hot end temperature was $1000 \mathrm{~K}$ obtained by electric heaters of $185 \mathrm{~W}$ power. The whole unit weighed about $7 \mathrm{~kg}$.

Military applications of $\mathrm{V}-\mathrm{M}$ cycle refrigerators have been seriously considered. Some details about the theory of operation and thermodynamic loss analysis are given by White (1976). Donabedian (1972) has compiled the performance data of developmental V-M cycle refrigerator models of Philips laboratories, Garret AiResearch. Kinergetics, Hughes Aircraft Co. and RCA Corporation, USA.

3.2j Pulse tube cryorefrigerator: This very simple device was reported by Gifford \& Longsworth (1964a). Its schematic diagram is shown in figure 14. When the inlet valve is opened, the gas in the tube is compressed rapidly and then there is a quiescent period when heat is rejected to the cooling water in the second heat exchanger. Then, the outlet valve is opened and the pressure rapidly decreases producing cooling. Cold gas passes through the regenerator, and gets warmed again before going out. The cycle repeats.

Clearly, for a $100 \%$ efficient regenerator the refrigeration produced will be equal to the heat rejected in the second heat exchanger, assuming perfect insulation. Gifford \& Longsworth (1964b), have shown how the pulse tube can be cascaded. With a two-stage unit they obtained $140 \mathrm{~K}$ and with a three-stage unit, $100 \mathrm{~K}$. Longsworth (1967), investigated the effect of geometrical factors and gas properties on the performance of the pulse tube. The heat pumping mechanism in the pulse tube was discussed in detail by Gifford \& Longsworth (1966). With a view to military applications, Ackermann (1970) has made analytical investigations, and has shown that to achieve a performance competitive to the $1 \mathrm{~W}, 77 \mathrm{~K}$ refrigerator,

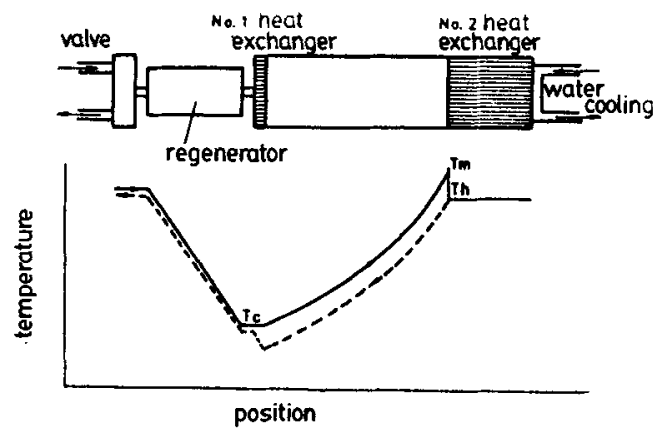

Figure 14. Schematic diagram of pulse tube refrigerator. 
two stages of cooling are required.

It may be noted that the pulse tube is a very simple device; however, it appears that no commercial models of this type of refrigerator have entered the market so far.

All the methods considered above (except the first one i.e. the use of liquid cryogen) have one thing in common, viz, all of them use gas as the working substance. In connection with these cycles, Radebaugh (1978, pp. 7-43), has observed as follows:

(i) In a practical, high speed Stirling machine, time is too short for isothermal heat transfer to occur; so the cycle tends towards an ideal Otto cycle with two adiabatic and two isochoric processes.

(ii) The G-M cycle which has 'free' adiabatic expansion and two isobars becomes similar to the Ericsson cycle at slow speeds i.e. two isothermals and two isobars. At high speeds, it becomes similar to the Brayton cycle i.e. with two isobars and two adiabatics.

The next three methods to be considered, viz, adiabatic demagnetization, $\mathrm{He}^{3} / \mathrm{He}^{4}$ dilution refrigeration and Pomeranchuk cooling are for operation in the milliKelvin temperature range and as already mentioned, find their applications mainly in research. A comprehensive review of these methods and their applications is given by Huiskamp \& Lounasmaa (1973).

$3.2 \mathrm{k}$ Adiabatic demagnetization: The adiabatic demagnetization method (Huiskamp \& Lounasmaa 1973; Lounasmaa 1974; Betts 1976) originally suggested by Debye (1926) and Giauque (1927), makes use of the fact that in some of the paramagnetic salts (e.g. iron ammonium alum, cerium magnesium nitrate etc.) the magnetic dipoles are randomly oriented even at temperatures of the order of $1 \mathrm{~K}$ i.e. their entropy is considerable even at that temperature. Hence, they can be ordered (or entropy reduced) by applying a high magnetic field ( $=30 \mathrm{kOe}$ ). This is analogous to isothermally compressing a gas in the gas refrigeration method. where the entropy of the gas is reduced. Then, if we adiabatically remove the magnetic field, the temperature will drop. Some of the disadvantages of this method are (Gopal 1977): field, the temperature will drop. Some of the disadvantages of this method are (Gopal 1977):

(i) it is a "single-shot" experiment and steady state experiments are difficult.

(ii) cooling capacity is small; so, large samples cannot be used;

(iii) a magnetic field is always present - hence, one cannot perform experiments which require absence of magnetic fields.

Figure 15a shows the $T-S$ diagram of a magnetic-ion subsystem. $(k \rightarrow i)$ represents isothermal magnetization and $(i \rightarrow f)$ represents adiabatic demagnetization from $i$ to $f$. Figure $15 \mathrm{~b}$ shows the schematic of the apparatus used for adiabatic demagnetization (Barron 1966). The paramagnetic salt is cooled to about $1 \mathrm{~K}$ in a pumped LHe bath. Then the specimen is magnetized and to facilitate the removal of heat of magnetization, helium exchange gas is used around the specimen. After magnetization is completed, the specimen is thermally isolated by pumping out the exchange gas and the magnetic field is reduced to zero and temperature falls.

Various paramagnetic salts generally used are: (i) manganous ammonium sulphate; (ii) gadolinium sulphate; (iii) ferric methyl ammonium alum: (iv) ferric ammonium alum; (v) chromium potassium alum; (vi) chromium methyl ammonium alum; (vii) cerium ethyl sulphate; and (viii) cerium magnesium nitrate. Of 


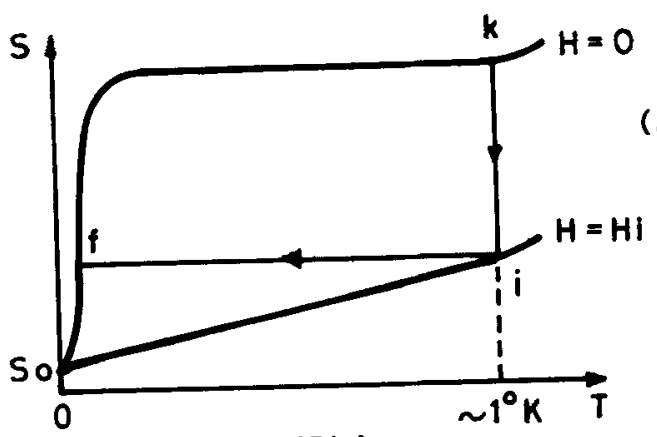

(a)

Fig. 15(a)

to vacuum pump
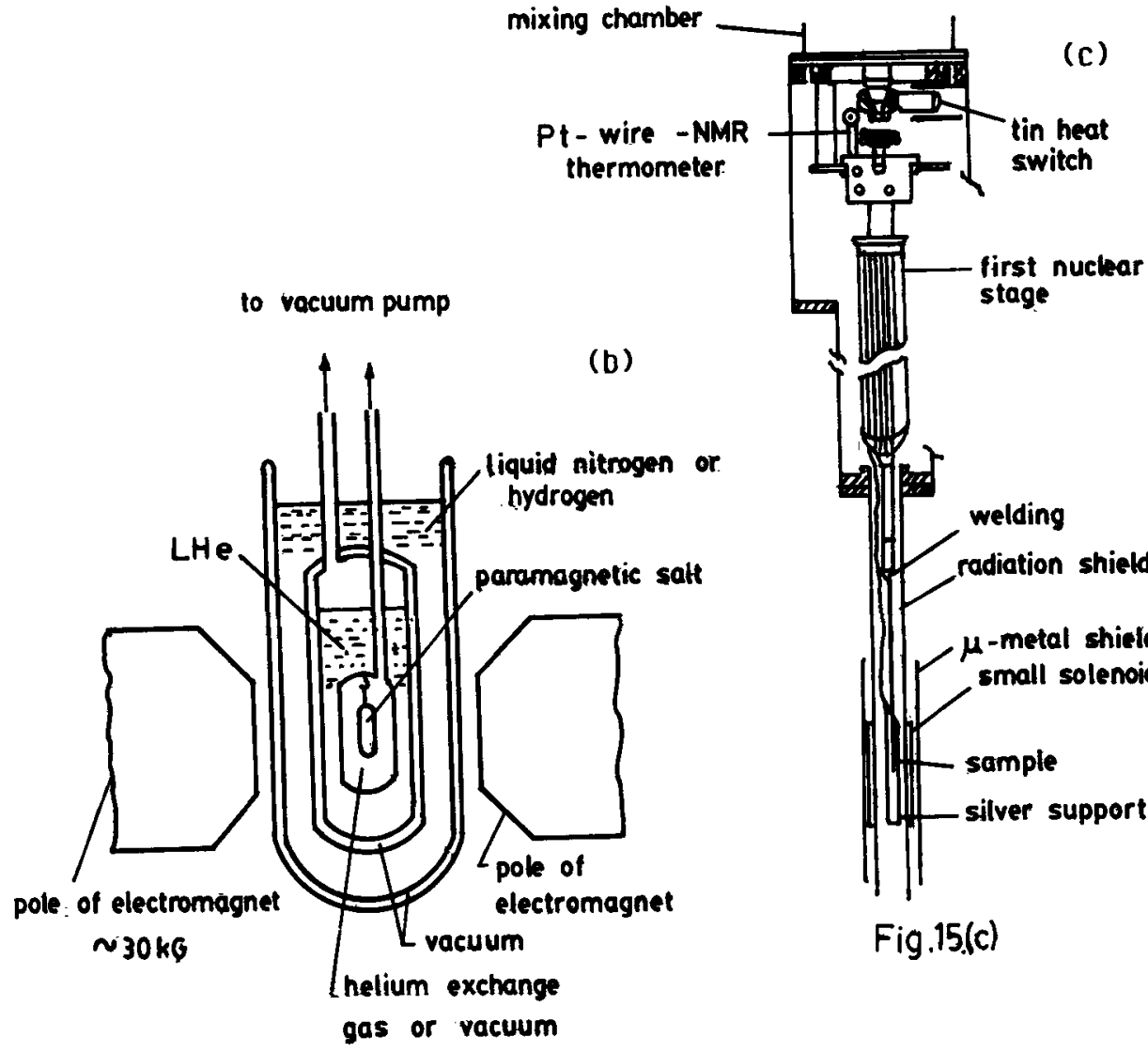

(b)

Figure 15a. T-S diagram for magnetic-ion subsystem. b. Adiabatic demagnetization apparatus. c. Cascade nuclear refrigerator.

these, the first two salts are suitable for achieving temperatures down to $0.2 \mathrm{~K}$ and the next four salts are suitable down to $50 \mathrm{mK}$. Cerium magnesium nitrate is 
particularly useful as a magnetic thermometer since it obeys Curie's law down to about $6 \mathrm{mK}$.

Kurti \& Simon (1934) obtained a temperature of $0.038 \mathrm{~K}$ starting with an initial temperature of $1.23 \mathrm{~K}$, with iron-ammonium alum as the working salt. The magnetic field used had a value of $14 \cdot 1 \mathrm{kOe}$. Heer et al (1954) built a magnetic refrigerator to operate below about $0.7 \mathrm{~K}$ using iron-ammonium alum as the working salt. To increase the thermal conductivity of the salt, $0.003 \mathrm{~m}$ long pieces of fine copper wire $\left(5 \times 10^{-5} \mathrm{~m}\right.$ dia) were embedded in salt pellets.

By adiabatic nuclear demagnetization, still lower temperatures in the microKelvin range are obtained. The basic principle is the same as for paramagnetic salts; however, since the nuclear magnetic moments are about 2000 times smaller than the electronic magnetic moments, to achieve significant change in nuclear spin entropy, the starting temperature should be about $20 \mathrm{mK}$ and the magnetic field, about 5 Tesla.

The final temperature after adiabatic demagnetization is roughly given by

$$
T_{f} / T_{i}=\left(B_{f}^{2}+b^{2}\right)^{1 / 2} / B_{i}
$$

where $T_{f}, T_{i}, B_{f}$ and $B_{i}$ are the final and the initial temperatures, and fields, respectively, and $b$ is the internal dipolar field $(b=0.3 \mathrm{mT}$ in copper $)$, (Lounasmaa 1984).

It should be noted that if the demagnetization is done all the way to zero field, no doubt a lower temperature will be reached, but the nuclear spin system would warm up very fast; instead, if the demagnetization is stopped at a moderate field (say 20-60 mT), the system will remain cold for a long enough time to perform some experiments, e.g. at a starting temperature of $10 \mathrm{mK}$ and initial field of 6 Tesla, if the demagnetization is done to zero field, final nuclear temperature will be $0.5 \mu \mathrm{K}$. For a practical value of heat leak of about $1 \mathrm{nW} / \mathrm{mol}$, temperature of the conduction electrons will be $0.7 \mathrm{mK}$; warming up time to $10 \mathrm{mK}$ will be about $9 \mathrm{~min}$. If demagnetization is done only to $19 \mathrm{mT}$, final nuclear temperature will be $32 \mu \mathrm{K}$, temperature of the conduction electrons will be $64 \mu \mathrm{K}$ and time to warm up to $10 \mathrm{mK}$ will be about 10 hours (Huiskamp \& Lounasmaa 1973).

Adopting the adiabatic demagnetization of nuclear spins of copper, Kurti et al (1956) obtained a temperature of about 20 microKelvin.

The lowest temperature reported so far is about 50 nanoKelvin, by Lounasmaa (1984) of Helsinki University, using the nuclear adiabatic demagnetization technique. The cascade nuclear refrigerator built by Lounasmaa's group is shown in figure $15 \mathrm{c}$. Here, the first nuclear stage is made of $10 \mathrm{~mol}$ of bulk copper and is cooled by a $\mathrm{He}^{3} / \mathrm{He}^{4}$ dilution refrigerator via a superconducting heat switch made of tin. The second nuclear stage is also of copper, but smaller in size (2-3 g). The two stages are weided together. The first and second stages are magnetized by two superconducting solenoids, of 8 and 7 Tesla fields, respectively. The final temperature reached in the second stage for the nuclear spin system is below $50 \mathrm{nK}$; however, the conduction electrons are still at about 50 microKelvin.

Two materials widely used for nuclear refrigeration are copper and $\mathrm{PrNi}_{5}$. The "hyperfine enhanced" praseodymium compound has more cooling capacity per unit volume and needs only about 2-3 Tesla field (Andres \& Lounasmaa 1982; Lounasmaa 1984). 
3.21 $\mathrm{He}^{3} / \mathrm{He}^{4}$ dilution refrigerator: This method was suggested by London (1951). However, the practical dilution refrigerator was built only fourteen years later by Hall et al (1966) in Manchester and by Neganov et al (1966) in Dubna. Unlike the adiabatic demagnetization method, the dilution refrigerator provides continuous refrigeration in the milliKelvin temperature range. The review article by Lounasmaa (1979a) describes a refrigerator which gave $2.0 \mathrm{mK}$. The following are the principles on which the dilution refrigerator works (Wood 1971; Haselden 1971):

(i) $\mathrm{LHe}^{3}$ and $\mathrm{LHe}^{4}$ are miscible with each other and remain in single phase above a temperature of $0.87 \mathrm{~K}$.

(ii) As the mixture is cooled to below $0.87 \mathrm{~K}$, two distinct phases are formed; the upper, lighter phase is rich in $\mathrm{He}^{3}$ and the lower, denser phase is rich in $\mathrm{He}^{4}$.

(iii) At these temperatures, entropy of superfluid $\mathrm{He}^{4}$ is negligible as compared to that of normal $\mathrm{He}^{3}$. So, $\mathrm{He}^{3}$ when dissolved in $\mathrm{He}^{4}$, behaves as though it is an expanding gas and the process is endothermic. So, if this is done adiabatically, temperature will fall.

(iv) $\mathrm{He}^{3}$ atoms diffuse through superfluid $\mathrm{He}^{4}$ from one place to another where $\mathrm{He}^{3}$ concentration is smaller.

(v) At $0.6 \mathrm{~K}$, vapour pressure of $\mathrm{He}^{4}=0.001$ torr and that of $\mathrm{He}^{3}=0.6$ torr. So, if heat is applied to the solution at $0.6 \mathrm{~K}, \mathrm{He}^{3}$ will evaporate preferentially. Embodying these principles Hall et al (1966) constructed and operated a dilution refrigerator which reached $0.065 \mathrm{~K}$.

Figure 16a shows a simplified flow diagram of a typical continuously operating dilution refrigerator (Arkharov et al 1981). The vacuum pump 1, which circulates $\mathrm{He}^{3}$, delivers the $\mathrm{He}^{3}$ gas at a pressure of about 67 to $80 \mathrm{kPa}(0.67-0.8 \mathrm{~atm})$. This stream is first cooled in an $\mathrm{LN}_{2}$ bath and an LHe bath and then to about $1 \mathrm{~K}$ in a pumped LHe bath. The liquefied $\mathrm{He}^{3}$ then passes through a capillary which controls its flow rate. Next, this stream enters a coil type still, 4 , whose temperature is 0.6 to $0.7 \mathrm{~K}$. Then this stream passes through a batch of heat exchangers where it is cooled by the return stream to a temperature $T_{i}$ and enters the mixing chamber, 6 .

In the mixing chamber the feed separates into two phases; the upper, lighter phase is pure $\mathrm{He}^{3}$ and the lower, denser phase is a dilute mixture $\mathrm{He}^{3}$ in $\mathrm{He}^{4}$. As the $\mathrm{He}^{3}$ atoms cross the boundary from the concentrated to the weak solution (i.e.
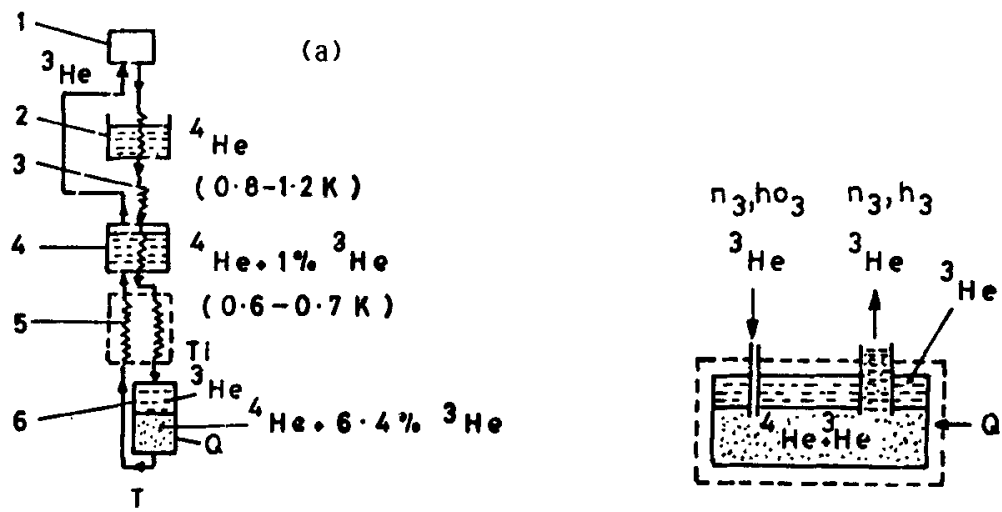

(b)

16a. $\mathrm{He}^{1} / \mathrm{He}^{4}$ dilution refrigerator. b. Mixing chamber. 
from top to bottom) cooling is produced. Next, the $\mathrm{He}^{3}$ atoms pass through the heat exchangers in the reverse order to the still where the liquid column ends. Here $\mathrm{He}^{3}$ is separated from $\mathrm{He}^{4}$ by supplying external heat. $\mathrm{He}^{3}$ vapours are removed by the vacuum pump and the vapours coming out of the still constitute more than $95 \%$ of $\mathrm{He}^{3}$ since the vapour pressure of $\mathrm{He}^{4}$ at $0.6 \mathrm{~K}$ is negligible. Referring to figure $16 \mathrm{~b}$, the quantity of heat absorbed during dilution, $Q$, is given by

$$
Q=\dot{n}_{3}\left(h_{3}-h_{03}\right) \text {, }
$$

where $\dot{n}_{3}=$ flow rate of $\mathrm{He}^{3}$ circulating, $\mathrm{mol} / \mathrm{s} ; h_{3}=$ enthalpy of dilute $\mathrm{He}^{3}, \mathrm{~J} / \mathrm{mol}$; $h_{03}=$ enthalpy of $\mathrm{He}^{3}$ entering the mixing chamber, $\mathrm{J} / \mathrm{mol}$.

We have, from Arkharov et al (1981),

$$
\begin{aligned}
& h_{03}=12 T_{i}^{2} \text { and } h_{3}=94 T^{2}, \text { and } \\
& Q=\dot{n}_{3}\left(94 T^{2}-12 T_{i}^{2}\right) .
\end{aligned}
$$

If the heat exchangers ( 5 in figure 16a) have a high efficiency, $\left(T_{i}-T\right)$ is small and $T_{i} / T \approx 1$. And we get

$$
Q=82 \dot{n}_{3} T^{2} \text {. }
$$

From the above, it can be seen that at $T / T_{i}=0 \cdot 36, Q=0$.

Heat exchangers are the critical components of a dilution refrigerator as can be seen from the above analysis. There have been three main streams of development in this area (Wood 1971):

(a) continuous flow type of heat exchanger, first developed by Hall et al (1966). It is simple, has fewer joints and a small volume. Its disadvantage is that the heat transfer area available is small. It is suitable upto temperatures around $50 \mathrm{mK}$. (b) a system of concentric tubes, used successfully by Neganov et al (1966). It provides large heat transfer area and has less resistance to flow. However, volume of $\mathrm{He}^{3}$ required is rather large.

(c) sintered metal elements pioneered by Wheatley (1969). Surface areas of the order of $100 \mathrm{~cm}^{2} / \mathrm{cm}^{3}$ are easily obtained. Sintered copper heat exchangers have been used upto $10 \mathrm{mK}$ and sintered silver heat exchangers were used in the dilution refrigerators achieving $2 \mathrm{mK}$.

Frossati (1978) has explained in detail the design aspects of these heat exchangers which were employed in the dilution refrigerator which reached $2 \mathrm{mK}$ at Grenoble.

At Leiden, Pennings et al (1976) have built a dilution refrigerator working on a different concept; here, $\mathrm{He}^{4}$ is circulated rather than $\mathrm{He}^{3}$. Its advantage is that no heat exchangers of large surface area are needed because heat is transferred directly between the two counterflowing liquid phases. Kapitza thermal boundary resistance between the two liquid streams is therefore eliminated. This refrigerator reached $7.9 \mathrm{mK}$.

Dilution refrigerators are adaptable to special requirements. Niinikoski (1976) has described a horizontal dilution refrigerator used for study of spin-frozen, polarized proton targets. This refrigerator gives $10 \mathrm{~mW}$ at $200 \mathrm{mK}$ with $\dot{n}_{3}=7 \mathrm{mmol} / \mathrm{s}$; and $150 \mathrm{~mW}$ at $500 \mathrm{mK}$ with $\dot{n}_{3}=25 \mathrm{mmol} / \mathrm{s}$. Dilution refrigeration has become very popular for continuous operation in the milliKelvin region and has practically replaced the adiabatic demagnetization of paramagnetic salts. More than 100 dilution refrigerators are now in operation (Lounasmaa 1984). 
Commercially, the dilution refrigerators are now available with cooling powers ranging from $60 \mu \mathrm{W}$ to $2000 \mu \mathrm{W}$ at $100 \mathrm{mK}$ (and upto $6 \mu \mathrm{W}$ at $10 \mathrm{mK}$ ) and guaranteed minimum temperatures ranging from $20 \mathrm{mK}$ to $4.5 \mathrm{mK}$ (Product Bulletin 1984). Details of some commercially available models are given in table 15.

3.2m Pomeranchuk cooling: This method, proposed first by Pomeranchuk (1950) in Russia, makes use of the following special properties of $\mathrm{He}^{3}$ :

(i) pure liquid $\mathrm{He}^{3}$ will not solidify even at $0 \mathrm{~K}$ without the imposition of a pressure of about 34 bar $\left(34 \times 10^{5} \mathrm{~Pa}\right)$;

(ii) the melting curve has a minimum at about $0.3 \mathrm{~K}$, the pressure at this point being 29 bar $\left(29 \times 10^{5} \mathrm{~Pa}\right)$;

(iii) below $0.3 \mathrm{~K}$ the solid has higher entropy than the liquid, i.e., the solid is more disordered than the liquid;

(iv) therefore, if a mixture of solid and liquid $\mathrm{He}^{3}$ initially at equilibrium at a point below $0.3 \mathrm{~K}$ on the melting curve, is compressed adiabatically, the liquid will gradually be converted to solid and the system temperature will drop.

Figure 17a shows the fusion curve for $\mathrm{He}^{3}$. At $0.32 \mathrm{~K}$ and a pressure of $2.9 \mathrm{MPa}$ (29 atm), the fusion curve has a minimum. Thus an increase in pressure at $T<0.32 \mathrm{~K}$ will reduce the temperature (path A-B).

Figure 17b shows the $T-S$ diagram for $\mathrm{He}^{3}$ at $T<0.5 \mathrm{~K}$. (Arkharov et al 1981). Cooling by adiabatic compression proceeds in two stages:

(i) $\mathrm{He}^{3}$ is liquefied and precooled to below $0.32 \mathrm{~K}$, point $\mathrm{A}$.

(ii) Solidification of $\mathrm{He}^{3}$ by isentropic compression of the liquid (A-B). Now the temperature falls by $\Delta T=T_{i}-T_{f}$.

Entropy of solid $\mathrm{He}^{3}$ at $T<0.32 \mathrm{~K}$ remains nearly constant and is given by

$$
S_{\text {solid }}=R \cdot \ln (2) \text {. }
$$

Entropy of the liquid phase varies linearly as follows:

$$
S_{\text {liquid }} \approx 18 T \text {. }
$$

\begin{tabular}{|c|c|c|c|c|c|}
\hline \multirow[b]{2}{*}{ Name of firm } & \multirow[b]{2}{*}{ Model } & \multirow{2}{*}{$\begin{array}{c}\text { Minimum } \\
\text { guaranteed } \\
\text { temperature }(\mathrm{mK})\end{array}$} & \multicolumn{2}{|c|}{ Cooling power } & \multirow{2}{*}{$\frac{(\mu \mathrm{W})}{(100 \mathrm{mK})}$} \\
\hline & & & $(10 \mathrm{mK})$ & $(25 \mathrm{mK})$ & \\
\hline $\begin{array}{l}\text { Oxford Instruments, } \\
\text { UK }\end{array}$ & $\begin{array}{r}75 \mathrm{~S} \\
400 \mathrm{~S} \\
1000 \mathrm{~S} \\
2000 \mathrm{~S}\end{array}$ & $\begin{array}{l}20 \\
4 \cdot 5 \\
4 \cdot 5 \\
4 \cdot 5\end{array}$ & $\begin{array}{l}- \\
2 \cdot 5 \\
6 \\
-\end{array}$ & $\begin{array}{l}1 \cdot 5 \\
20 \\
60 \\
-\end{array}$ & $\begin{array}{r}75 \\
400 \\
1000 \\
2000\end{array}$ \\
\hline $\begin{array}{l}\text { S.H.E. Corporation, } \\
\text { USA }\end{array}$ & $\begin{array}{l}510 \\
520 \\
530 \\
550\end{array}$ & $\begin{array}{l}20 \\
4 \cdot 5 \\
20 \\
3.5\end{array}$ & $\frac{2}{6}$ & $\begin{array}{l}\overline{20} \\
\overline{60}\end{array}$ & $\begin{array}{r}400 \\
400 \\
1500 \\
1500\end{array}$ \\
\hline $\begin{array}{l}\text { Leybold-Heraeus, } \\
\text { Germany }\end{array}$ & $\begin{array}{l}\text { MK-100 } \\
\text { MK-400 } \\
\text { MK-1000 }\end{array}$ & $\begin{array}{l}15 \\
15 \\
15\end{array}$ & $\begin{array}{l}- \\
- \\
-\end{array}$ & $\begin{array}{l}- \\
- \\
-\end{array}$ & $\begin{array}{r}10 \\
35 \\
100\end{array}$ \\
\hline
\end{tabular}

Table 15. Commercial $\mathrm{He}^{3} / \mathrm{He}^{4}$ dilution refrigerators

Source: Product Bulletins of respective firms. 

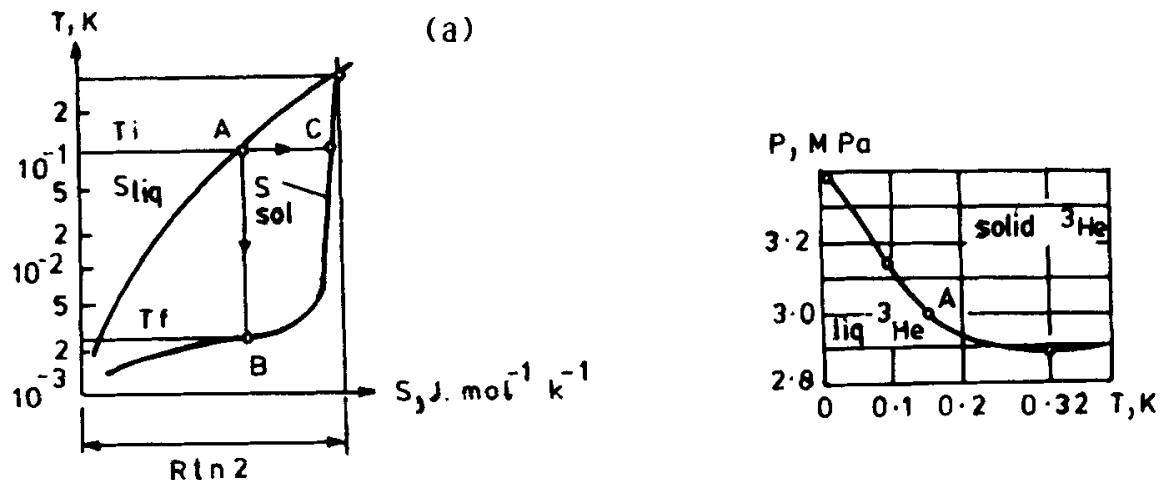

(b)

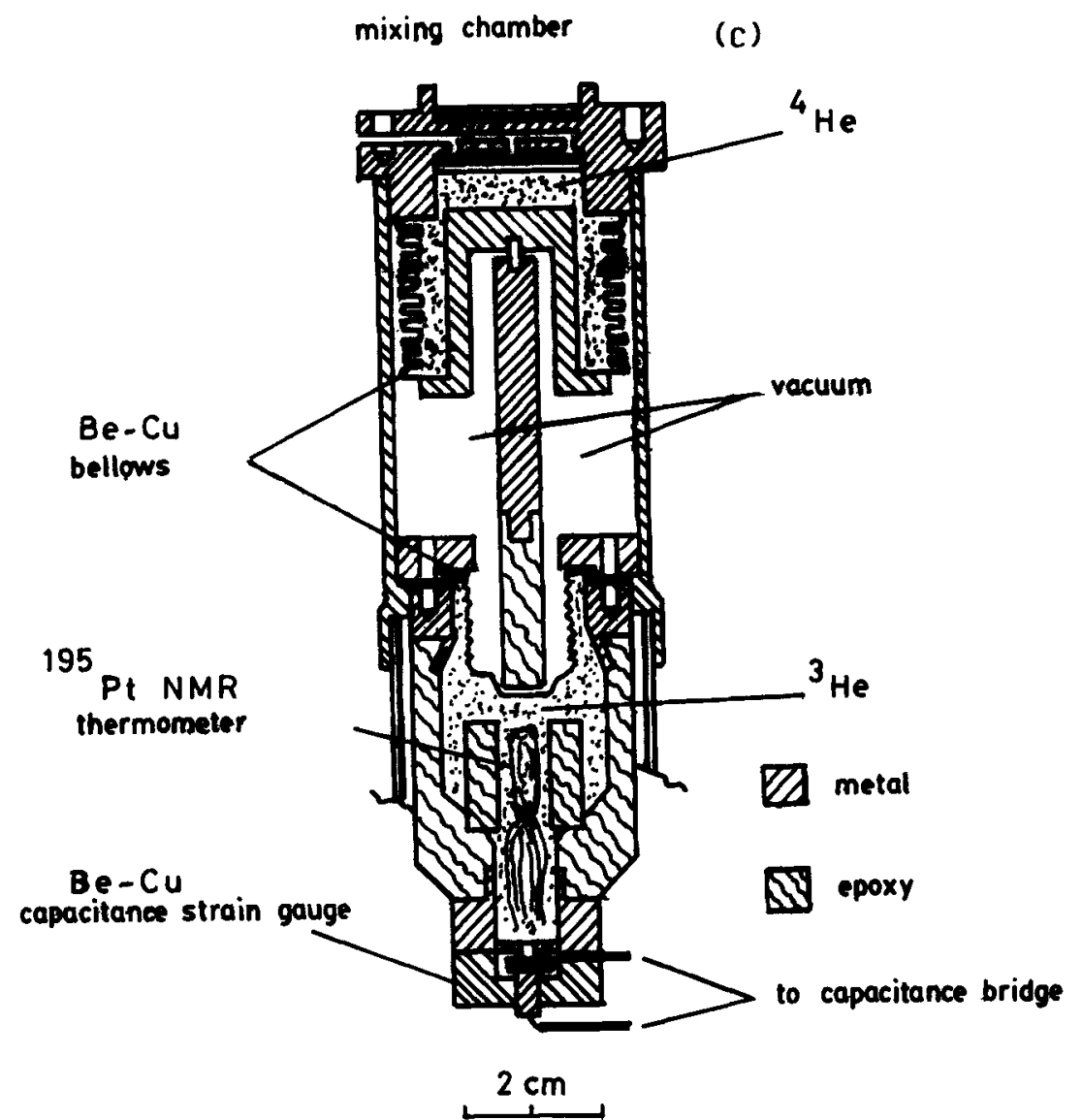

Figure 17a. Entropy diagram for liquid and solid $\mathrm{He}^{3}$. b. Fusion curve for $\mathrm{He}^{3}$. c. Pomeranchuk cooling cryostat of Osheroff et al (1972).

Therefore, the quantity of absorbed heat is given by

$$
Q=T[R \ln (2)-18 T] \mathrm{J} / \mathrm{mol} \text {. }
$$


The main experimental difficulty is in compressing the $\mathrm{He}^{3}$ by addition of extra $\mathrm{He}^{3}$ into the low temperature cell; the connecting tube has to pass through the solid region in the phase diagram and therefore gets blocked. This problem is solved by other means such as having a flexible $\mathrm{He}^{3}$ cell and squeezing it with a $\mathrm{He}^{4}$ pressurizer.

The second practical difficulty is the frictional heat generated as the solid $\mathrm{He}^{3}$ crystals are crushed during the increase of pressure. This happens roughly when the fraction of solid $\mathrm{He}^{3}$ in the $\mathrm{He}^{3}$ cell is about $30 \%$. This problem is solved to some extent by resorting to a lower starting temperature, e.g., if the starting temperature is $0.15 \mathrm{~K}$, when the pressure is increased and the temperature drops to about $0.08 \mathrm{~K}$, the cell would already have $30 \%$ of the contents solidified; however, if a lower starting temperature of $25 \mathrm{mK}$ is adopted, the solid concentration becomes $30 \%$ only below $3 \mathrm{mK}$ (Lounasmaa 1969).

Wheatley (1969) describes a Pomeranchuk refrigerator which was precooled to about $25 \mathrm{mK}$ using a $\mathrm{He}^{3} / \mathrm{He}^{4}$ dilution refrigerator and obtained a final temperature of $2-4 \mathrm{mK}$.

Figure 17c shows a Pomeranchuk cell used by Osheroff et al (1972). It is attached to the mixing chamber of a dilution refrigerator for precooling. Two berylliumcopper bellows connected by a rigid shaft act on the principle of hydraulic pressure amplifier; with a $\mathrm{He}^{4}$ pressure of the order of $10 \mathrm{~atm}$ in the upper chamber the lower compartment which contains about $12 \mathrm{~cm}^{3}$ of $\mathrm{He}^{3}$ charge gets compressed sufficiently to solidify the entire charge. In the $\mathrm{He}^{3}$ cell, the bellows open out during compression thus preventing the crushing of the solid $\mathrm{He}^{3}$ formed inside the convolutions. The final temperature reached was about $2 \mathrm{mK}$.

Pomeranchuk cooling is useful for cooling $\mathrm{He}^{3}$ itself and studying its properties. In this method, the problem of Kapitza boundary resistance associated in cooling at very low temperatures is avoided. Production of highly polarized $\mathrm{He}^{3}$ targets, study of the phase and entropy diagrams of $\mathrm{He}^{3}$ under a magnetic field etc. are possible by this method. It should also be noted that superfluid phases of $\mathrm{He}^{3}$ - $\mathrm{A}$ and $\mathrm{He}^{3}-\mathrm{B}$ were discovered by Osheroff et al. (1972), using the Pomeranchuk cell described above.

Like adiabatic demagnetization, this method is also of a "single-shot" type. Another limitation is the high frictional dissipation because of the high viscosity of liquid $\mathrm{He}^{3}$.

In the range $25 \mathrm{mK}-6 \mathrm{mK}$, refrigeration produced in Pomeranchuk cooling, $Q$, is proportional to $T$ whereas the refrigeration produced in the case of the dilution refrigerator is proportional to $T^{2}$. Thus at $5 \mathrm{mK}$ the Pomeranchuk cooling is greater by an order of magnitude as compared to dilution refrigeration (Huiskamp \& Lounasmaa 1973).

\section{Conclusion}

In this review, various cryogenic refrigeration methods to obtain temperatures in the cryogenic range have been described. Use of a liquid cryogen and practically all the gas refrigeration methods have been explained. In addition, three exclusive methods to obtain temperatures in the milliKelvin/microKelvin range viz. adiabatic demagnetization, $\mathrm{He}^{3} / \mathrm{He}^{4}$ dilution refrigeration and Pomeranchuk cooling have 
also been described. Data about some of the commercially available refrigerators/ cryogenerators have also been given.

We thank the staff of the Drawing Office of the Technical Physics \& Prototype Engineering Division and Shri P Kush of the Cryogenics Section for their help. One of us (MT) wishes to express the gratitude to Shri S S Ramamurthi for constant encouragement during this work.

\section{List of symbols}

Symbols used are defined in the text as and when they occur. The following gives only a general list of nomenclature used.

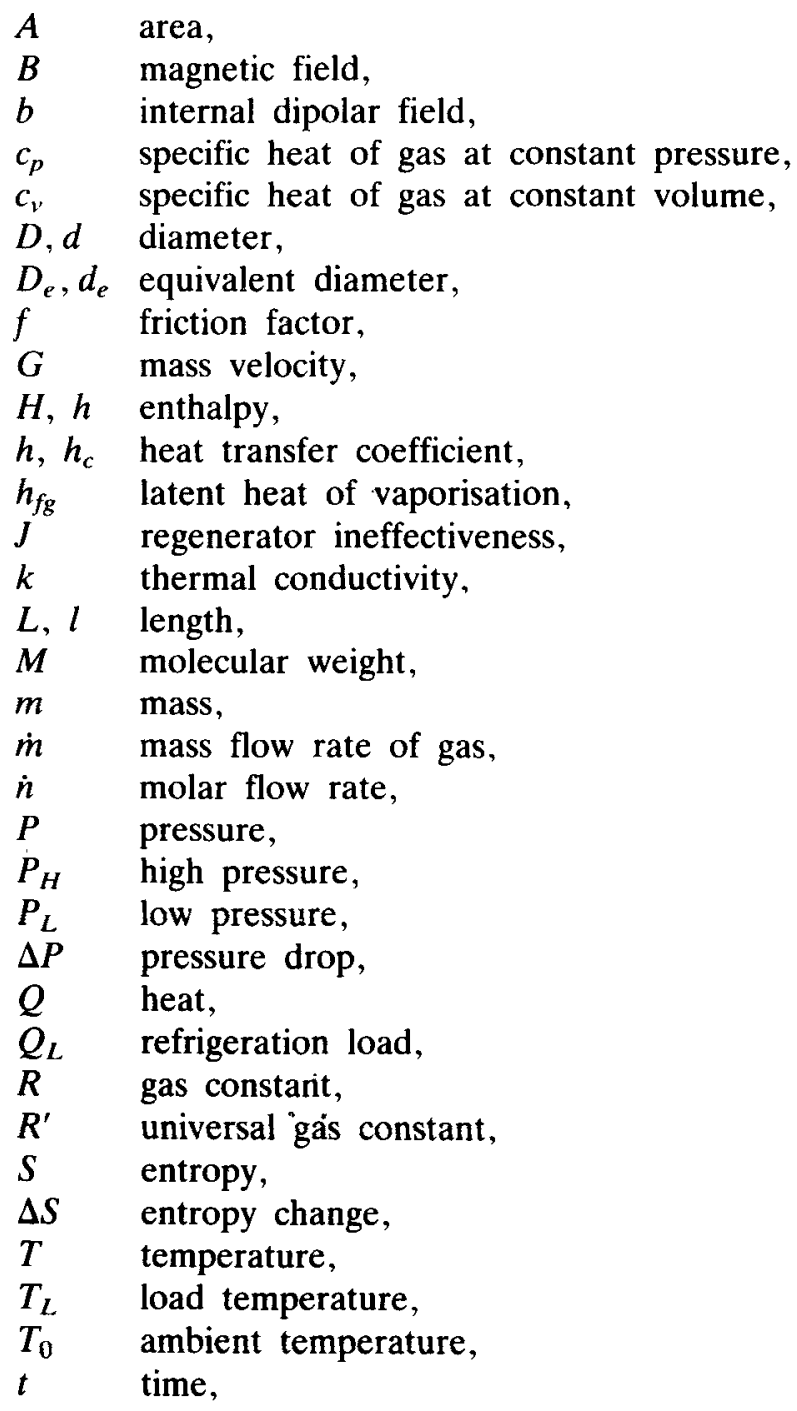




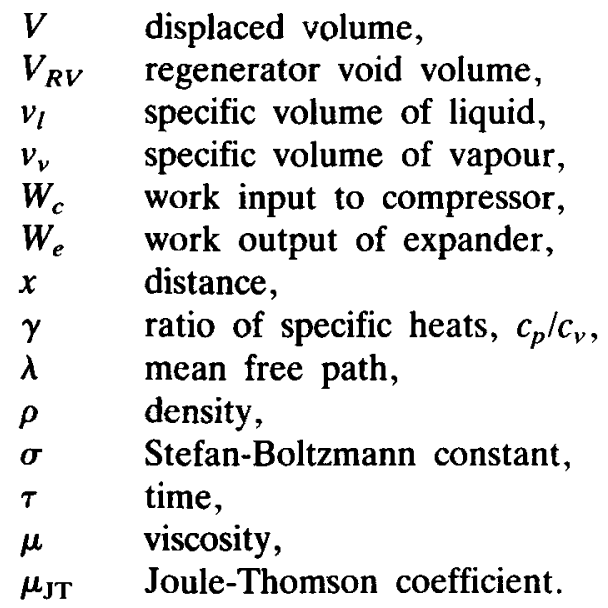

\section{Dimensionless groups:}

$\mathrm{Nu} \quad$ Nusselts number $=h \cdot D_{e} / k$,

$\operatorname{Pr} \quad$ Prandtl number $=c_{p} \cdot \mu / k$,

Re Reynolds number $=G \cdot D_{e} / \mu$,

St Stanton number $=h / G \cdot c_{p}$.

\section{References}

Ackermann R A 1970 Investigation of Gifford-McMahon cycle and pulse tube cryogenic refrigerators, Research and Development Technical Report ECOM-3245 (United States Army Electronics Command)

Ackermann R A, Gifford W E 1971 Adv. Cryog. Eng. 16: 221-229

Andres K, Lounasmaa O V 1982 Prog. Low Temp. Phys. 8: 221-229

Arkharov A, Marfenina J, Mikulin Ye 1981 Theory and design of cryogenic systems (Moscow: Mir Publishers) chap. 4

Bailey C A 1971 Advanced cryogenics (ed.) C A Bailey (London: Plenum Press) chap. 12

Barron R 1966 Cryogenic systems (New York: McGraw Hill)

Betts D S 1976 Refrigeration and thermometry below one Kelvin (Sussex: Univ. Press)

Blaser C, Kurtcuoglu K 1981 Sulzer Tech. Rev. 1: 21-26

Clarke M E, Gardner J B 1967 Proc. of Ist Int. Cryog. Eng. Conf. Tokyo and Kyoto, Japan (Guildford, Surrey: Iliffe Sci. Technol.) pp. 273-274

Collins S C, Cannaday R L 1958 Expansion machines for low temperature processes (Oxford: Univ. Press)

Crawford A H 1970 Cryogenics 10: 28-37

Croft A J 1976 Cryogenic laboratory equipment (New York: Plenum Press)

Croft A J 1971 Advanced cryogenics (ed.) C A Bailey (London: Plenum Press) chap. 7

Cryogenic data chart 1969 British Oxygen Co., UK

Damiani M, Getraud R, Senn A 1972 Sulzer Tech. Rev. Special number "Nuclex 72": 1-5

Daniels A, du Pre H K 1971 Philips Tech. Rev. 32(2): 49-56

Dean J W, Mann D B 1965 The Joule-Thomson process in cryogenic refrigeration systems, NBS Tech. Note 227

Debye P 1926 Ann. Phys. 81: 1154-1160

Doll R, Eder F X 1964 Adv. Cryog. Eng. 9: 561-564

Donabedian M 1972 Survey of Cryogenic Cooling Techniques, Aerospace Report No. TR-0073(390101)-1

Eber N 1980 Cryogenics 20: 183-189 
Fowler W B 1982 Int. Cryog. Eng. Conf. ICEC-9, pp. 831-837

Frossati G 1978 J. Phys. (Paris) C39: 1578-1589

Gasser M G, Sherman A, Beale W 1981 Refrigeration for cryogenic sensors and electronic systems (eds)

J E Zimmermann, D B Sullivan, S E McCarthy (Washington: Natl. Bur. Stand.) Spl. Publ. No. 607

Giauque W F 1927 J. Am. Chem. Soc. 49: 1864-1870

Gifford W E 1961 Prog. Cryog. 3: 51-73

Gifford W E 1966 Adv. Cryog. Eng. 11: 152-159

Gifford W E 1967 Proc. of lst Int. Cryog. Eng. Conf. Kyoto, Tokyo, Japan (Guildford, Surrey: Iliffe Sci. Technol.) pp. 221-224

Gifford W E 1970 Cryogenics 10: 23-27

Gifford W E, Hoffman T E 1961 Adv. Cryog.Eng. 6: 82-94

Gifford W E, Longsworth R C 1964a J. Eng. Ind. 86: 264-268

Gifford W E, Longsworth R C 1964b Int. Adv. Cryog. Eng. 10: 69-79

Gifford W E, Longsworth R C 1966 Adv. Cryog. Eng. 11: 171-179

Gifford W E, McMahon H O 1960a Progress in Refrigeration Science and Technology-Proc. of 10th Int. Congress of Refrigeration 1: 100-104

Gifford W E, McMahon H O 1960b Adv. Cryog. Eng. 5: 354-367

Gifford W E, McMahon H O 1960c Adv. Cryog. Eng. 5: 368-372

Gifford W E, Withjack E M 1969 Adv. Cryog. Eng. 14: 361-369

Giger U 1968 Sulzer Tech. Rev. 4: 1-6

Giger U, Pagani P, Trepp Ch 1974 Sulzer Tech. Rev. 2: 1-7

Giger U, Quack H, Senn A 1975 Sulzer Tech. Rev. Special number "Nuclex 75": 1-7

Gopal E S R 1977 J. Phys. Educ. 4: 1-10

Haarhuis G J 1978a Cryogenics 18: 656-658

Haarhuis G J 1978b Proc. of 7th Int. Cryog. Eng. Conf. (ICEC-7) London (London: IPC Sci. Technol.) pp. $421-427$

Hall H E, Ford P J, Thompson K 1966 Cryogenics 6: 80-88

Haselden G G (ed.) 1971 Cryogenic fundamentals (London: Academic Press) chap. 2

Heer C V, Barnes C B, Daunt J G 1954 Rev. Sci. Instrum. 25: 1088-1098

Hoare F E, Jackson L C, Kurti N 1961 Experimental cryophysics (London: Butterworths)

Hrycak P 1963 Cryogenics 3: 23-26

Huiskamp W J, Lounasmaa O V 1973 Rep. Prog. Phys. 36: 423-496

Jacobs R B 1962 Adv. Cryog. Eng. 7: 567-571

Jain M B 1980 Development and performance investigation of free displacer cryorefrigerator Ph.D. thesis, Indian Institute of Technology, Bombay

Kohler J W L, Jonker C D 1954a Philips Tech. Rev. 16: 69-78

Kohler J W L, Jonker C D 1954b Philips Tech. Rev. 16: 105-115

Kurti N 1971 Cryogenic fundamentals (ed.) G G Haselden (London: Academic Press) chap. 1

Kurti N, Robinson H N H, Simon F E, Spohr D A 1956 Nature (London) 178: 450-453

Kurti N, Simon H E 1934 Nature (London) 133: 907, cited in White (1968)

Lehrefeld D 1983 Infrared Phys. 23: 77-84

London H 1951 Proc. Int. Conf. Low Temperature Physics (Oxford: Clarendon Lab) p. 157

Longsworth R C 1967 Adv. Cryog. Eng. 12: 608-618

Longsworth R C 1970 Adv. Cryog. Eng. 16: 195-204

Lounasmaa O V 1969 Sci. Am. 221/6: 26-35

Lounasmaa O V 1974 Experimental principles and methods below $1 \mathrm{~K}$ (London: Academic Press)

Lounasmaa O V 1979a $J$. Phys. E12: 668-675

Lounasmaa O V 1979b Phys. Today 32(12): 32-41

Lounasmaa O V 1984 Adv. Cryog. Eng. 29: 551-563

Mann D B, Sixsmith H, Wilson W A, Birmingham W B 1963 Adv. Cryog. Eng. 8: 221-227

Mendelssohn K 1966 The quest for absolute zero (London: McGraw Hill)

Muhlenhaupt R C, Strobridge T R 1968 An analysis of the Brayton cycle as a cryogenic refrigerator, NBS Tech. Note No. 366

Neganov, Borisov N, Liburg M 1966 Soviet Phys. JETP (Engl. Transl.) 23: 959-967

Niinikoski T O 1976 Proc. 6th Int. Cryog. Eng. Conf. (London: IPC Sci. Technol.) pp. 102-110 Osheroff D D, Richardson R C, Lee D M 1972 Phys. Rev. Lett. 28: 885-888 
Patzelt A, Pullach, Stephan A 1973 Cryogenic engineering - the field of activity of Linde A. G. - handling temperatures between $22 \mathrm{~K}$ and $1.8 \mathrm{~K}$, Linde Reports on Science and Technology 19 , pp. 3-24

Pennings N H, de Bruyn Ouboter R, Taconis K W 1976 Physica B84: 249-253

Pewitt E G 1971 Adv. Cryog. Eng. 16: 19-26

Pitcher G K, du Pre F K 1970 Adv. Cryog. Eng. 15: 447-451

Pomeranchuk I 1950 Zh. Eksp. Teor. Fiz. (USSR) 20: 919-924

Product Bulletin 1970 Cryogenic Technology Inc., USA

Product Bulletin 1977 Balzers, USA

Product Bulletin 1978a Laboratory cryogenic systems, Air Products and chemicals Inc., USA

Product Bulletin 1978b British Oxygen Co, UK

Product Bulletin 1979a Philips, Eindhoven, Netherlands

Product Bulletin 1979b Sulzer Bros., Winterthur, Switzerland

Product Bulletin 1981 Leybold Heraeus, Germany

Product Bulletin 1982 Oxford Instruments, UK

Product Bulletin 1983a l'Air Liquide, France

Product Bulletin 1983b Split Stirling Refrigerator RH-820, no. TL-206, l'Air Liquide, France

Product Bulletin 1983c Linde AG, Germany

Product Bulletin 1984 S.H.E. Corporation, USA

Quack H 1978 Sulzer Tech. Rev. Special number "Nuclex 78": 14-18

Radebaugh R 1978 Applications of closed cycle cryocoolers in small superconducting devices (Washington: Natl. Bur. Stand.) Spl. Publ. No. 508

Rose-Innes A C 1973 Low temperature laboratory techniques 2nd edn. (London: The English Universities Press)

Rule T T, Qvale E B 1968 Adv. Cryog. Eng. 14: 343-352

Scott R B 1959 Cryogenic engineering (New York: Van Nostrand)

Sixsmith H 1984 Adv. Cryog. Eng. 29: 511-523

Sixsmith H, Wilson W A $1964 \mathrm{~J}$. Res. Natl. Bur. Stand. C68: 101-114

Strobridge T R 1968 A hundred years of helium Helium - Symposia Proceedings, pp. 39-56

Strobridge T R, Chelton D B 1967 Adv. Cryog. Eng. 12: 576-584

Stuart R W, Cohen B M, Hartwig W H 1970 Adv. Cryog. Eng. 15: 428-435

Stuart R W, Hogan W H, Rogers A D 1967n Adv. Cryog. Eng. 12: 564-575

Tada E, Hiyama T, Kato T, Takhashi O, Shimamoto S 1982 Int. Cryog. Eng. Conf. (ICEC-9), pp. 93-96

Vance R W, Duke W M 1962 Applied cryogenic engineering (New York: John Wiley and Sons)

Vander Ster J, Kohler J W L 1958 Philips Tech. Rev. 20: 177-187

Walker G 1973 Stirling cycle machines (Oxford: Clarendon Press)

Wheatley J C 1969 Adv. Cryog. Eng. 15: 415-421

White G K 1968 Experimental techniques in low temperature physics 2nd edn. (Oxford: Clarendon Press)

White R 1976 Vuilleumier cycle cryogenic refrigeration, US Air Force Tech. Report AFFDL-TR-76-17

Wood M F 1971 Advanced cryogenics (ed.) C A Bailey (London: Plenum Press) chap. 9

Zemansky M W 1968 Heat and thermodynamics 5th edn. (Tokyo: McGraw Hill and Kogakusha) chap. 12

Zimmermann J E, Radebaugh R 1978 Applications of closed cycle cryocoolers to small superconducting devices (Washington: Natl. Bur. Stand.) Spl. Publ. No. 508

Zimmermann J E, Sullivan D B 1982 A study of design principles for refrigerators for low power cryoelectronic devices, NBS Tech. Note 1049 